University of Wollongong

Research Online

Faculty of Engineering - Papers (Archive)

Faculty of Engineering and Information

Sciences

$1-1-2008$

\title{
An EBSD investigation of interstitial-free steel subjected to equal channel angular extrusion
}

Azdiar A. Gazder

University of Wollongong, azdiar@uow.edu.au

Wenquan Q. Cao

Monash University

Christopher H.J. Davies

Monash University

E V. Pereloma

University of Wollongong, elenap@uow.edu.au

Follow this and additional works at: https://ro.uow.edu.au/engpapers

Part of the Engineering Commons

https://ro.uow.edu.au/engpapers/1202

\section{Recommended Citation}

Gazder, Azdiar A.; Cao, Wenquan Q.; Davies, Christopher H.J.; and Pereloma, E V.: An EBSD investigation of interstitial-free steel subjected to equal channel angular extrusion 2008, 341-352.

https://ro.uow.edu.au/engpapers/1202

Research Online is the open access institutional repository for the University of Wollongong. For further information contact the UOW Library: research-pubs@uow.edu.au 


\title{
AN EBSD INVESTIGATION OF INTERSTITIAL-FREE STEEL SUBJECTED TO EQUAL CHANNEL ANGULAR EXTRUSION
}

\author{
Azdiar A. Gazder ${ }^{*}$, Wenquan Cao², Christopher H.J. Davies², Elena V. Pereloma ${ }^{1}$ \\ ${ }^{1}$ School of Mechanical, Materials \& Mechatronics Engineering, University of Wollongong, New South Wales 2522, Australia \\ 2 Department of Materials Engineering, Monash University, Victoria 3800, Australia
}

\begin{abstract}
The microstructural evolution of interstitial-free (IF) steel subjected to $\Phi=90^{\circ}$ Equal Channel Angular Extrusion (ECAE) for up to 4 passes via routes $A, B_{A}, C$ and up to 8 passes via routes $B_{C}$ was studied using Electron Back-Scatter Diffraction (EBSD). Routes $\mathrm{B}_{\mathrm{C}}$ and $\mathrm{B}_{\mathrm{A}}$ recorded the smallest grain size and aspect ratios and the largest average misorientation and area fraction of high-angle grain boundaries (HAGBs). During multiple passes, microstructure refinement continues until a convergence in effective subgrain and grain diameters occurs; following which the rate of HAGB formation reduces slightly. The percentage rise in the number of $\Sigma 3$ and random boundaries should be correlated with the operation of recovery mechanisms in ultrafine grained IF-steel rather than linking such special boundaries with twinning during ECAE. Compared to the scaling factor Hall-Petch (H-P) equation, the composite H-P equation indicates that although the low-angle boundaries (LAGBs) provide the maximum strengthening up to 8 passes, the contribution from HAGBs also increases with greater pass number.
\end{abstract}

Keywords: equal channel angular extrusion (ECAE); equal channel angular pressing (ECAP); electron back-scattering diffraction (EBSD); coincidence site lattice (CSL); steel; Hall-Petch

* Corresponding Author:

\section{Azdiar A. Gazder}

(Formerly with the Department of Materials Engineering, Monash University, Victoria 3800, Australia)

Phone: + 612 4221 5904; $\quad$ Fax: $\quad+612$ 4221 3662; Email: $\underline{\text { Azdiar@uow.edu.au }}$ 


\section{Introduction}

Equal Channel Angular Extrusion (ECAE) is one of a number of severe plastic deformation (SPD) processes that result in bulk ultrafine grained (UFG) materials. As-ECAE deformation microstructures may be characterised by a hierarchy based on their individual misorientation relationships [1]. In order to correlate such deformation substructures with their overall mechanical behaviour, an accurate and statistically valid description of the bulk microstructure is essential. Thus a delineation between "grains" or "subgrains", "cell-block boundaries" (comprising parallel microbands and/or lamellar boundaries also defined as geometrically necessary boundaries, GNBs) or "cell boundaries" (incidental dislocation boundaries, IDBs for mixed tilt and twist walls) in as-deformed substructures is mandatory. To this end, highresolution Electron Back-Scattering Diffraction (EBSD) techniques involving the use of fieldemission guns coupled with automated Kikuchi pattern identification and analysis processes are used to produce representative measurements of a material's "state" with nanometer resolution over large sample areas [2]. However, in common with other experimental investigations of UFG metals, such EBSD measurements have focussed mainly on fcc materials such as $\mathrm{Al}[3]$ and $\mathrm{Cu}$ $[4,5]$.

In order to establish the effect of the number of passes and employed processing route on the microstructural refinement of bcc materials, the present study employs EBSD to characterise IFsteel specimens previously subjected to room temperature $\Phi=90^{\circ}$ ECAE after 1 pass $(\mathrm{N}), 4$ passes via routes $A, B_{A}$ and $C$ and up to 8 passes via route $B_{C}$ processing. Microstructural evolution after various passes and processing routes is compared by providing quantitative distributions of subgrain and grain sizes and misorientation relationships. Finally, this information is applied to the composite [6] and scaling factor [7] Hall-Petch (H-P) equations in order to understand the strengthening contributions of low and high -angle boundary populations for up to 8 passes via route $\mathrm{B}_{\mathrm{C}}$ processing.

\section{Experimental and Analytical Procedure}

Commercially available hot-rolled IF-steel plate (Fe-0.003C-0.15Mn-0.03Al-0.08Ti-0.007Si0.01P-0.005S-0.001N wt\%) was obtained from BlueScope Steel Limited, machined into $20 \times 20$ $\times 80 \mathrm{~mm}^{3}$ billets, annealed at $1023 \mathrm{~K}$ for one hour and allowed to furnace cool. The distribution of grain size in the annealed material was measured using optical microscopy and fitted by a log-normal distribution with a mean grain size of $140 \pm 10 \mu \mathrm{m}$. The annealed billets were subjected to room temperature ECAE for 1 pass, 4 passes and/or up to 8 passes via routes $A, B_{A}$, 
$\mathrm{B}_{\mathrm{C}}$ and $\mathrm{C}$, using a $\Phi=90^{\circ}, \Psi=0^{\circ}$ die-set with sharp inner and outer corners (Figure 1). Further experimental details are described in $[8,9]$.

For EBSD analysis, only $x$ (or ED) -plane specimens cut from the center of the stable billet length after 1 pass, 4 passes (via routes $A, B_{A}$ and $C$ ) and 2 to 8 passes (via route $B_{C}$ ) were used. Each specimen was ground and polished up to $1 \mu \mathrm{m}$ surface finish followed by light etching using OPS Silica solution. The EBSD measurements were performed on a LEO-1530 Field Emission Gun Scanning Electron Microscope (FEG-SEM) fitted with a Nordlys-II ${ }^{\mathrm{TM}}$ EBSD detector operating at $20 \mathrm{kV}$ and $\times 15 \mathrm{k}$ magnification. Two orientation image maps of $15 \times 20 \mu \mathrm{m}^{2}$ were scanned from the center of the $x$-plane of each sample using a step size of $80 \mathrm{~nm}$.

Post-processing of the raw data was performed by using the VMAP software package [10] to improve the angular resolution up to $1^{\circ}$. Thereafter, analysis of the EBSD maps was undertaken using the HKL - Channel $5^{\mathrm{Tm}}$ software package. In the 256 colour relative Euler maps, the primary colours are proportional to the three Euler angles. It should be remembered that these Euler angles refer to sample directions when inserted into the microscope and therefore do not generally correspond to the Euler angles conventionally used to describe materials deformed with orthotropic symmetry (for e.g. - rolling). Thus the colours provided by the software represent the different Euler angles of each volume element of the specimen with a $5^{\circ}$ angular variation. In many cases, regions of similar orientation have similar colours. However this may not always be the case due to discontinuities in Euler space [11].

For any particular deformation condition, the two field scans were analysed individually, following which their average and standard deviation results were tabulated. The average misorientation $\left(\theta_{A V G}\right)^{1}$ and misorientation profile (in $2^{\circ}$ bins) was measured using the $>1^{\circ}$ lower cut-off value in order to reduce the effects of noise. The effective subgrain $\left(d_{1^{\circ}-15^{\circ}}\right)$, grain $\left(d_{15^{\circ}-62.8^{\circ}}\right)$ and average $\left(d_{A V G}\right)$ diameters were calculated using the misorientation definition of the various boundary types and are discussed below. Boundaries with angles $\theta \leq 15^{\circ}$ are classified as low-angle (or LAGBs) whereas boundaries with $15^{\circ}<\theta \leq 62.8^{\circ}$ are denoted as highangle boundaries (or HAGBs). As suggested by Bowen [12], further distinctions between the HAGBs can also be drawn by subdividing them into medium $\left(15^{\circ}<\theta \leq 30^{\circ}\right.$, or MAGBs), mediumhigh $\left(30^{\circ}<\theta \leq 45^{\circ}\right.$, or MHAGBs) and very-high $\left(45^{\circ}<\theta \leq 62.8^{\circ}\right.$, or VHAGBs) -angle boundaries.

The intercept lengths ( $L_{X}$ and $L_{Y}$ ) were measured along the local horizontal and vertical axes of the field scan reference frame (which correspond to the macroscopic TD and ND global axes,

\footnotetext{
${ }^{1}$ From hereon, the subscript term ' $A V G$ ' refers to a microstructural parameter averaged over the entire misorientation range extending from $1^{\circ}$ up to $62.8^{\circ}$.
} 
respectively). The average aspect ratio $(\lambda)$ was calculated using the grain reconstruction method after imposing a boundary definition of $\theta \geq 1^{\circ}$. It is understood that due to substructure inclination with respect to the local horizontal and vertical axes the intercept lengths across the ED-plane samples will be underestimated compared to other billet planes. However the data trends remain unaffected. In order to account for reasonable grain shapes, the values of $d_{A V G}$, $d_{1^{\circ}-15^{\circ}}$ and $d_{15^{\circ}-62.8^{\circ}}$ were calculated using the average linear-intercept and then multiplied by 1.75 to return an "effective diameter" value [13]. Thus the effective diameters are calculated by assuming intercept lengths relationships as being essentially smaller than the "true" diameter of the subgrain/grain.

Special boundary relationships were identified using the coincidence-site-lattice (CSL) theory via the Brandon (or proximity) criterion [14] which describes the maximum tolerance of misorientation angle $(\Delta \Theta)$ from an exact CSL relationship by:

$$
\Delta \Theta=\Theta_{m} \Sigma^{-1 / 2}
$$

where, $\Theta_{m}$ is the maximum misorientation angle for a low-angle boundary $\left(1^{\circ}<\theta<15^{\circ}\right)$. The $\Sigma 1$ (or LAGBs), $\Sigma 3$ (or twin) and $\Sigma 5-29 \mathrm{~b}$ boundaries are expressed as a percentage of the total number of intersecting boundaries. The various special boundaries shared by only the HAGB population $\left(\theta \geq 15^{\circ}\right)$ are also computed. In both cases, the boundaries that do not satisfy the Brandon criterion are designated as "random" grain assemblies.

In order to characterise the mechanical strength, similar as-ECAE billets were machined into round tensile samples of $\varnothing 4 \mathrm{~mm}$ diameter and $15 \mathrm{~mm}$ gauge length. Room temperature uniaxial tensile testing was undertaken on a screw-driven Instron 4505 operating at a crosshead speed of $0.5 \mathrm{~mm} \mathrm{~min}^{-1}$; with elongation measured by a $10 \mathrm{~mm}$ gauge length extensometer. Using a purpose-written tolerance-divergence MATLAB ${ }^{\circledR}$ subroutine, an optimised elastic modulus was estimated by comparing a bulk texture -based modulus model [15] with experimental tensile test data for each as-ECAE condition. Average elastic modulus estimates of $195.3 \mathrm{GPa}$ for the annealed condition and $170.3 \mathrm{GPa}$ after 8 passes via route $\mathrm{B}_{\mathrm{C}}$ were computed. The $\sim 13 \%$ reduction in elastic modulus estimates between coarse grained and as-ECAE IF-steel agrees well with moduli-based experimental studies on UFG materials [16-19]. Following this, the $0.1 \%$ $\left(\sigma_{0.1}\right)$ and $0.2 \%\left(\sigma_{0.2}\right)$ proof stresses and the ultimate tensile strengths $\left(\sigma_{U T S}\right)$ were calculated. Only changes in mechanical strengths are correlated with refinement of the subgrain and grain deformation microstructure. Further details regarding procedure and modulus estimates are described in [20]. 


\section{Results}

After $\mathrm{N}=1$ (Figure 2), the initially coarse grains of the annealed steel were replaced by a substructure comprising a large area fraction of subgrains and a very small area fraction of grains (enclosed by high-angle boundaries). Here the shear direction is out-of-plane as indicated by the ED, TD and ND -axes. The abundance of low-angle boundaries (comprising $\sim 1 \mu \mathrm{m}$ subgrains) indicate that significant grain subdivision occurs after the first pass to accommodate the large imposed strain. The smooth transition in subgrain colour contrast indicates a close crystallographic orientation within and between the individual low-angled substructures. In terms of the aspect ratio of the ellipsoidal subgrain after the first pass, the long-axis is approximately parallel to TD-axis while the short-axis is parallel to ND-axis.

After 2 passes via route $B_{C}$ processing (Figure 3(a)), subgrain refinement occurred and slightly greater numbers of high-angle boundaries also appear. The elongated areas start to get subdivided by the HAGBs while a network of LAGBs is still present inside most grains. However the distribution of LAGBs within these grain boundaries tends to be heterogeneous. Some larger grains contain high densities of LAGBs whereas other relatively smaller individual grains do not contain any LAGBs. The high aspect ratio $(\lambda)$ grains are elongated along the TD-axis.

After 4 passes via route A, the deformation substructure remains elongated (Figure 4(a)). In contrast to the $\mathrm{N}=1$ condition, greater fragmentation of the lamellae along both the TD and ND axes is observed; concomitant with a clear increase in HAGB population. Since route A processing is characterised by the continuous unidirectional rotation of the shear plane in the billet about the TD, successive shear patterns tend to remain more or less constrained within previously created dislocation boundaries. Such behaviour correlates well with the previously observed gradual changes in the fiber-like bulk textures (comprising relatively strong individual orientation densities) for this processing route $[8,9]$.

In theory, the return of a refined but equiaxed substructure should occur after even-numbered passes via route C. However, Figure 4(c) clearly indicates regions of elongated substructures after 4 passes. These results are in agreement with previous TEM and texture work that also found the retention of elongated lamellae and qualitatively shear-type textures after evennumbered passes [8]. The latter was attributed to the complex deformation history during $\Phi=$ $90^{\circ}$ ECAE which included: (i) deviation from ideal simple shear caused by friction the billetdie interface and L-shaped chip formation, (ii) variations in billet deformation due to changes in hardening behaviour, (iii) increasing stability of dislocation substructures and grain-scale deformation heterogeneities $[8,21,22]$. 
Irrespective of processing route and number of passes, the first bin of the misorientation distribution (Figure 5) contains high $f(\theta)$ values as it also comprises a small intrinsic scanning error associated with remnants of orientation noise. However, with increasing imposed strain a steady decline of misorientations with angles $\leq 5^{\circ}$ is observed.

During the post-processing of some field scans, large spikes were seen at $\sim 30^{\circ}$ and $60^{\circ}$ misorientation ${ }^{2}$. A previous investigation on IF-steel [12] attributed this anomaly to the unusual incidence of $\Sigma 13 \mathrm{~b}$ and $\Sigma 3$ coincidence-site-lattice (CSL) boundaries due to misindexing by the EBSD software. In the case of severely deformed bcc iron this phenomenon arises because $27.8^{\circ}\langle 111\rangle$ and $60^{\circ}\langle 111\rangle$ orientations are more prone to pseudo-symmetry than others [23]. In order to minimise such errors and false interpretations associated with such errors, all maps were cleaned by disregarding the effect of the $\Sigma 13 b$-boundaries.

As expected, trends similar to the $f(\theta)$-values are also observed in case of the area fraction estimate ( $\left.A_{F} \%\right)$ of the various misorientation classes (Figure 6). After the first pass the fewest grains are found between misorientations of $30^{\circ}-62.8^{\circ}$ (or MHABs and VHAGBs (Figures 6(c and d)). With more passes, the contribution of misorientations above $30^{\circ}$ increases and is accompanied by a decrease in fraction of LAGBs (Figure $6(\mathrm{a})$ ). A maximum of $\sim 60 \%$ HAGB area fraction is noted after 6 passes via route $B_{C}$ processing. Similar values have been previously reported for IF-steel [12], $\mathrm{Al}$ and Al-alloys [24-27] and $\mathrm{Ni}$ [28] processed by warm and room temperature ECAE and Armco iron subjected to HPT [29].

As imposed strain increases, so does the average misorientation of all boundaries $\left(\theta_{A V G}\right)$ (Figure 7a) due to the evolution of higher-angled boundary substructures with greater passes (Figure 7c). However, the average misorientation for low angle boundaries remains constant up to three passes of route $B_{C}$ and two of route $B_{A}$ (Figure $7 b$ ). The effects of processing route are also readily apparent as $\theta_{A V G}$-values after 4 passes is the highest for routes $\mathrm{B}_{\mathrm{A}}$ followed by route $\mathrm{B}_{\mathrm{C}}$ and then by routes $\mathrm{A}$ and $\mathrm{C}$, and can be directly associated with the magnitudes of their initial $f(\theta)$-values.

Consistent with ECAE deformation, the average effective diameters obtained after $\mathrm{N}=1$ indicate significant grain refinement compared to the as-annealed condition $(\sim 140 \pm 10 \mu \mathrm{m}$ at $\mathrm{N}=0)$. As seen in Figure 8(a), multiple passes produces a further reduction in the $d_{A V G}$-values but the rates of substructure refinement is markedly reduced after $\mathrm{N}>3$. Beyond 5 passes, the values of

\footnotetext{
${ }^{2}$ The affected cases included EBSD maps after 1 pass, $4 \mathrm{~B}_{\mathrm{A}}, 3-7 \mathrm{~B}_{\mathrm{C}}$ passes.
} 
low and high -angled substructures converge as further refinement causes the $d_{15^{\circ}-628^{\circ}}$ to approach their $d_{1^{\circ}-15^{\circ}}$ counterparts (Figure 8(d)). Throughout, the aspect ratio of the structures remains approximately constant (Figure 9). In terms of the smallest recorded grain size and aspect ratio and the largest average misorientation and HAGB area fractions, routes $\mathrm{B}_{C}$ and $\mathrm{B}_{\mathrm{A}}$ are approximately equivalent, followed by routes $\mathrm{A}$, and $\mathrm{C}$. These results are in agreement with the strain path dependence of microstructural evolution defined by Zhu and Lowe [30].

The equivalent circle diameter $\left(d_{E C D}\right)$ method has also been used for all boundaries with $\theta \geq 1^{\circ}$ (Figure $8(\mathrm{~d})$ ). Here the $d_{E C D}$ describes that diameter of a circle whose area is the same as the measured area of a subgrain/grain [29]. As stated by Humphreys et al. [11], the $d_{E C D}$ is related to the 'true' grain diameter $(\bar{D})$ through the relationship:

$d_{E C D}=0.816 \bar{D}$

In this respect, the $d_{E C D}$ size measurements presented in Figure 8(d) are an underestimate of the actual (or 'true') substructure diameters by approximately $\sim 23 \%$ over the entire misorientation range. For example, the $d_{E C D}$ values stabilise at $\sim 0.33 \mu \mathrm{m}$ when averaged between $\mathrm{N}=3$ to 8 for route $\mathrm{B}_{\mathrm{C}}$ processing. Applying Eq. (2) suggests that the true diameter $(\bar{D})$ is $\sim 0.4 \mu \mathrm{m}$; which approximates the average spacing between boundaries measured via TEM [8].

\section{Discussion}

This discussion will focus first on the microstructural evolution in IF-steel and then (due to the relative scarcity of information on as-ECAE steels) compare the results with more commonly examined fcc metals such as aluminium and copper. Secondly, we will examine the mechanical behaviour of as-ECAE IF-steel and the relative contributions of the various microstructural features to overall material strengthening. 


\subsection{Microstructural evolution}

Microstructural evolution during the ECAE of the IF-steel can be separated into two periods. The first period is found below four passes (Figures 2, 3(a-c) and 4) during which relatively rapid refinement of regions bounded by high-angle boundaries (Figure 8) is accompanied by a decline in the volume fraction of low angle boundaries (Figure 6(a)) and increases in the fraction of high-angle boundaries (Figure 6(d)) and the average misorientation (Figure 7(a)). The second period occurs at greater than four passes (Figures $3(\mathrm{~d}-\mathrm{g})$ and 4 ), once the average effective diameter of the LAGBs and HAGBs has converged (Figure 8(d)) and is characterised by a flattening of the misorientation distribution and attenuation of the attendant measures of microstructural evolution (Figures 6-9).

While this general trend of microstructural development with increasing pass number appears to be similar for all process routes, variations in the rates of microstructural evolution do exist. For example, the misorientation statistics and subgrain / grain sizes after 4 passes via route $\mathrm{C}$ corroborate previous investigations that found consistently lower rates of refinement for this processing route [31-33]. Under ideal route $C$ conditions, shear during an even-numbered pass should annihilate the dislocation structure created during an odd-numbered pass. But in the present case, deviations from ideal simple shear and the increasing stability of deformation substructures with greater strain $[8,22]$ prevents the return of the original grain shape and crystallographic orientation throughout the sample volume. The resultant local strain variations cause a build-up of dislocation boundaries in these areas. However, the overall rate of misorientation build-up remains extremely slow as rates of texture evolution are reduced and HAGBs are unable to increase their area due to successive distortions and reversals still occurring along approximately the same strain path [34].

Compared to our limited measurements made on routes $A, B_{A}$ and $C$, microstructural evolution to a quasi-stable structure appears to be most rapid via route $\mathrm{B}_{\mathrm{C}}$. Again, this observation is in common with numerous studies on fcc metals. We thus turn our attention to route $\mathrm{B}_{\mathrm{C}}$ in more detail.

Microstructural evolution comprises grain subdivision during the initial $(\mathrm{N} \leq 3)$ passes and rapid increases in the very high-angle boundary fraction at later passes (Figure 6(d)). The increase in misorientation occurs due to the production of deformation-induced HAGBs by grain splitting into coarse primary deformation bands and with the previous high-angle boundaries accumulating even greater misorientation. However, multiple passes also results in a slightly diminished rate of medium and medium-high -angle boundary formation, especially after $\mathrm{N} \geq 6$ (Figures 6 (b and c)). This is especially discernible after convergence of grain and subgrain sizes 
occurs (Figure 8(d)). The persistence of the LAGB structures even after a large number of passes $(\sim 40 \%$ of the boundary area fraction at $\mathrm{N}=6)$ is due to the ongoing formation of cell structures as a result of the imposed strain and localised recovery effects.

In common with previous studies $[12,35,36]$, the relative flattening of the misorientation distributions tends to occur faster than a corresponding change in the frequency misorientations to even higher class intervals (Figure 5). As suggested in [37-39], subgrain walls formed by the re-arrangement of trapped glide dislocations during one pass act as further barriers to dislocation propagation in successive passes. The various low-angled subgrains within the HAGBs select different combinations of slip systems to accommodate the next increment of strain during multi-pass ECAE [40]. In the case of such deformation microstructures, it is energetically favourable to activate fewer than the five slip systems required by von Mises theory. As deformation proceeds, each substructure rotates to the nearest stable end-orientations and results in both, the generation of new boundaries and a further rotation of pre-existing boundaries to even higher angles of misorientation [39]. Theoretically this process should continue endlessly; with further subdivision within these HAGBs into areas of LAGBs. By contrast, the present results show that the average grain size undergoes very large refinement between 1 and 3 passes until it approaches the effective subgrain diameter after 4 passes. Between 5 and 8 passes, a progressive break-up of high aspect ratio substructures also occurs in some localised areas. Even then the $d_{15^{\circ}-62.8^{\circ}}$-values tend to remain roughly equivalent with increasing numbers of passes.

On the other hand, route $\mathrm{B}_{\mathrm{C}}$ is considered to be a quasi-orthogonal processing regime; with the third and fourth passes reversing the shear imparted during passes one and two respectively. Thus while strain redundancy is still active, the rotation of the billet with successive passes forces the activation of fresh sets of slip systems, which in turn create new barriers to slip. It can be inferred that at lower passes the overall mechanical properties would be dictated by the interactions of the predominantly low-angled microstructure; as demonstrated in Section 4.2.

While lattice rotation effects cannot be neglected [41], larger area fractions of high-angled boundaries are produced after multiple passes due to increased magnitudes of dislocation storage at the cell/subgrain boundaries [29]. As stated by Embury [42], dislocation density at the boundaries for highly strained materials is characterised by an upper limit and shares an inverse relationship with the square of the dislocation spacing. Correspondingly, increasing the levels of imparted strain enhances the likelihood of activation of mechanical annihilation processes (involving in-situ local recovery effects [42]) and results in even larger boundary misorientation angles $[28,43]$. The end result of such dislocation accumulation and recovery is 
the formation of dense dislocation substructures with ever higher angles of misorientation between them.

It can also be speculated that after $N \geq 4$, the rise in the HAGB population should provide increasing mechanical strengthening contributions. Although the LAGB spacing remains larger than their HAGB counterparts in highly strained materials, the increasing area fractions of HAGBs will tend to affect overall mechanical behaviour as the LAGBs are unable to provide a continuous network to accommodate further deformation [12]. It can be surmised that since the ratio of LAGB to HAGB spacing is approximately constant by this stage, further changes in their individual contributions to overall mechanical strengthening would be a result of variations in area fractions and average misorientation.

Previous investigations [12, 39] also stressed the need for a generalised definition of a true and stable ultra-fine grained material as that which comprises: (i) HAGBs with an average spacing less than $1 \mu \mathrm{m}$ and, (ii) whose proportion of HAGB volume fraction exceeds $70 \%$. The latter criterion was based on experimental evidence of materials with relatively few LAGBs forming a dominant HAGB network; which in turn is said to inhibit discontinuous recrystallisation upon annealing [34, 39, 44].

However, in the present study the HAGB population plateaus after reaching a maximum of $\sim 60 \%$ at $\mathrm{N}=6$. Initially this suggests that either a greater number of passes are required or that the field scans are not statistically valid for making generalisations over the entire billet volume. However, when the presence of LAGBs is coupled with recovery phenomena during ECAE, it is surmised that the above definition of an ultra-fine grained material (which was applied mainly to fcc Al alloys [34, 44]) may not hold for bcc IF-steel.

Alternatively and in agreement with [39], it is seen here that HAGB formation is discontinuous and occurs on fine length scales until the grain size converges with the subgrain size at $\mathrm{N} \geq 4$. This in turn results in the smallest available length scale for dislocation generation/annihilation. If this phenomenon is assumed to define the formation of a true ultra-fine grained material, an amended definition that helps compare between various UFG materials should state: (i) approximately equivalent average subgrain/grain sizes for both, low and high -angled boundaries and, (ii) a majority HAGB population range. 


\subsubsection{Special boundaries characterisation}

Twins are a potent contribution to the strengthening of fcc metals [45] and have been observed previously in severely deformed $\mathrm{Cu}$ [46-49]. In this study, increasing numbers of passes resulted in a decrease in the percentage of $\Sigma 1$ (or LAGBs) boundaries and an increase in the boundaries of higher misorientation (Figures 5 and 6, Table 1). Two passes also results in an increase of higher index ( $\Sigma 5-29 \mathrm{~b}$ ) boundaries followed by a plateau after $\mathrm{N} \geq 3$. In most cases, the percentages associated with the $\Sigma 3$ and $\Sigma 5-29 \mathrm{~b}$ boundaries in the HAGB population alone (values in parenthesis in table 1) are approximately double those in the total boundary population and these results agree with an investigation on nanocrystalline Armco iron subjected to room temperature HPT [29]. Also in common are the approximately $\sim 1-2 \%$ total boundary fraction that comprise $\Sigma 3$ boundaries.

In other studies undertaken by us on the same material, extensive TEM analyses $[8,9]$ have failed to reveal structures with twin morphologies. While the presently employed EBSD step size prohibits the unambiguous identification of twins smaller than $80 \mathrm{~nm}$ width, at least some of the boundaries should have been identifiable. It must also be noted that even a random grain distribution will indicate the presence of some $\Sigma 3$ boundaries and the values depicted in Table 1 are within range of the $\Sigma 3(1.6 \%)$ and random (89\%) boundaries for a Mackenzie distribution comprising only grain boundaries [25]. This suggests that deformation twinning may not be as prevalent in IF-steel and is in agreement with Meyers et al. $[50,51]$ who noted that unlike fcc metals, the twinning domain decreases with smaller grain size and significant plastic deformation in the case of bcc iron. As a consequence, twinning can be discounted as a strengthening mechanism in as-ECAE IF-steel. Rather the presence of $\Sigma 3$ boundaries and increasing fraction of random grain assemblies with greater pass numbers should be correlated with the operation of recovery mechanisms during ECAE which tend to favour low-energy boundary configurations $[52,53]$.

\subsection{Correlating microstructure to mechanical strength}

The high strength of as-ECAE materials is generally attributed to substructure refinement. Thus it is reasonable to discuss the stress dependence of such deformed materials in relation to their smallest averaged microstructural feature (in this case, the subgrain size $\left.\left(d_{1^{\circ}-15^{\circ}}\right)\right)$. When the yield stresses are plotted as a function of $1 / \sqrt{d_{1^{\circ}-15^{\circ}}}$ using the original Hall-Petch equation [54, 55], a linear relationship is obtained but errors with regard to the magnitudes of friction stress and strain hardening constants persist. This is usually attributed to deficiencies in the original 
formulation of the Hall-Petch equation which treats all boundaries as high-angled structures. In contrast, our (and other) experimental results indicate a large area fraction of subgrains and average misorientation values $\leq 15^{\circ}$ during the initial few passes $(\mathrm{N} \leq 3$ ) (Figures 6 and 7). Thus the failure of the Hall-Petch law results mainly from a misinterpretation of the average characteristics associated with the strengthening behaviours of the LAGBs and HAGBs in asdeformed materials. As a solution, Hansen et al. [6] proposed a "composite" Hall-Petch equation based on the linear additive strengthening contributions from both LAGBs (via dislocation hardening) and HAGBs (via Hall-Petch prediction) as follows:

$$
\begin{aligned}
& \sigma=\sigma_{0}+\sigma_{L A G B S}+\sigma_{H A G B S} \\
& \sigma=\sigma_{0}+M \alpha G b \sqrt{\rho_{L A G B S}}+\frac{k_{H P}}{\sqrt{d_{H A G B S}}}=\sigma_{0}+M \alpha G b\left[\sqrt{\frac{1.5 S_{V_{1^{\circ}-15^{\circ}}} \theta_{1^{\circ}-15^{\circ}}}{b}}\right]_{I D B}+\left[\frac{k_{H P}}{\sqrt{d_{15^{\circ}-62.8^{\circ}}}}\right]_{G N B}
\end{aligned}
$$

where, $\sigma_{0}$ is the friction stress and has been defined as either: (i) the internal resistance to the motion of a dislocation through the crystal lattice [56] or, (ii) the flow stress of an undeformed single crystal oriented for multiple slip or, (iii) the approximate yield stress of a coarse, untextured polycrystal [6]. In the present study $\sigma_{0}$ is regarded as the grain size independent term and includes strengthening contributions from solutes and particles but not dislocations. $M$ is the average Taylor factor from texture data [57], $\alpha$ is a constant $(=0.24), G$ is the shear modulus (in $\mathrm{MPa}$ ) calculated from the relationship between optimised elastic modulus and Poisson's ratio $(=0.29), b$ is the Burgers vector $\left(=2.48 \times 10^{-10} \mathrm{~m}\right)$ and $S_{V}$ is the boundary area per unit volume of IDBs $\left(\square \pi / 2 d_{1^{\circ}-15^{\circ}}\right) . k_{H P}$ is the strain hardening parameter (or grain size dependent term) related to the additional resistance to dislocation motion caused by the dislocation source density at grain boundaries $[6,58]$ and $d_{15^{\circ}-62.8^{\circ}}$ is the effective diameter of high-angle GNBs. Thus as deformation proceeds, low-angled grain boundaries (LAGBs) gradually transform into high-angled boundaries (HAGBs) and are rendered indistinguishable from original grain boundaries [6]. In this respect, the second term uses the misorientation $\left(\theta_{1^{\circ}-15^{\circ}}\right)$ of LAGBs while the last term accounts for HAGB strengthening.

The above Eq. (3) has not yet been applied to as-ECAE IF-steel, and thus the $k_{H}$-values for the material and the magnitude of contribution from the various boundary types are sought using the mechanical and EBSD data for up to 8 passes via route $B_{C}$ processing at $\Phi=90^{\circ}$ ECAE. Firstly, 
the $S_{V_{1^{-1}-15^{\circ}}}$ and $\rho_{\text {LAGBS }}$ values are calculated from EBSD data and then the value of $k_{H P}$ is optimised by a least squares fit between the experimental $\sigma_{0.1}, \sigma_{0.2}$ and $\sigma_{U T S}$ and their predicted values (Figure 10(a)). Consequently the $k_{H P}$ values were found to be $0.09,0.16$ and $0.25 \mathrm{MPa} \cdot \mathrm{m}^{0.5}$ respectively. The latter values are small but agree with published data on IF-steel warm-rolled up to $30 \%$ reduction [59]. As seen in Figure 10(b), the LAGBs provide the maximum strengthening via entanglement for up to 8 passes. The approximately constant subgrain strength with increasing pass number can be attributed to misorientation increases and subgrain refinement within the LAGB class interval remaining low $\left(\Delta \theta_{1^{\circ}-15^{\circ}}=1.5^{\circ}\right)$. Such behaviour also results in a similitude relationship $\left((d . \theta)_{1^{\circ}-15^{\circ}} / b \square\right.$ constant $)$ for the IDBs between 1 to 8 passes [36].

For any given pass, the increase in $k_{H P}$ values from $\sigma_{0.1}$ through to $\sigma_{U T S}$ is evidence of work hardening. The averaged strengthening effect of HAGBs $\left(=k_{H P} /(G b)\right)$ was $5.2 \pm 0.6,9.1 \pm 1.1$ and $14.6 \pm 1.7 \times 10^{3} \mathrm{~m}^{-0.5}$ between $\sigma_{0.1}$ through to $\sigma_{U T S}$ and is of the same order as nanocrystalline $\mathrm{Al}$, $\mathrm{Ni}$ and $\mathrm{Cu}$ compacted powders [6]. Beyond $\mathrm{N} \geq 4$ ongoing refinement produces increasing numbers of similarly sized low-angled subgrains and high-angled grains. The refinement of the latter also produces the slightly enhanced HAGB strengthening effect between passes. Overall this implies that the composite hardening equation is reasonable as all estimates remain within a $\pm 5 \%$ error margin of their experimental counterparts.

In contrast to the above Eq. (3), a simplified stress dependence in relation to the smallest observable microstructural feature (in this case, the subgrain size $\left(d_{1^{\circ}-15^{\circ}}\right)$ ) has also been suggested for as-deformed substructures [7]. Since a grain boundary is modelled as an array of dislocations in the lattice, the spacing between dislocations is inversely proportional to the boundary misorientation [60]. Previous reports also indicated no misorientation effects on the flow stress when the average misorientation is above a critical saturation angle (usually $15^{\circ}$ ) [61]. Accordingly, Li et al. [7] suggested a scaling factor in the H-P equation such that:

$$
\sigma_{0.2}=\sigma_{0}+k^{\prime} \sqrt{\frac{\left(\theta_{A V G} / 15^{\circ}\right)}{d_{1^{\circ}-15^{\circ}}}} \text { when } \theta_{A V G} \leq 15^{\circ} \text { or, } \quad \sigma_{0.2}=\sigma_{0}+\frac{k^{\prime}}{\sqrt{d_{1^{\circ}-15^{\circ}}}} \text { when } \theta_{A V G}>15^{\circ}
$$

where, $\sigma_{0.2}$ is the $0.2 \%$ proof stress and $\theta_{A V G}$ is the average misorientation for the entire range. 
Thus the H-P relationship can also be derived using $d_{1^{\circ}-15^{\circ}}$ and accounting for $\theta_{A V G}$ effects via scaling for up to 3 passes (Figure 11). Least squares optimised values of $\sigma_{0}=99.33 \mathrm{MPa}$ and $k^{\prime}=$ $0.57 \mathrm{MPa} \cdot \mathrm{m}^{0.5}$ were calculated and agree with published data $[62,63]$. As seen in Figure 11 , the Eq. (4) best-fit line is also comparable to cold-rolled IF-steel [7].

In two aspects Eqs. (3 and 4) are in agreement. Both results indicate that at least up to 3 passes mechanical strengthening is dictated by the low-angled subgrains as they are significantly smaller than the average grain size [64]. Secondly, at low to medium strains the LAGB resistance is proportional to the square root of misorientation [59].

It is understood that beyond $\mathrm{N} \geq 4$ and in accordance with Figure 7(a) the scaling factor was removed from Eq. (4) when $\theta_{A V G}$ exceeds $15^{\circ}$. But at the same time, ongoing grain refinement also produces a convergence of $d_{1^{\circ}-15^{\circ}}$ and $d_{15^{\circ}-62.8^{\circ}}$-values (Figure 8(d)). As a consequence, Eq. (4) inadvertently suggests a change in strengthening mechanism to HAGBs by simply reverting back to the original H-P formulation and negating subgrain contributions entirely.

In contrast, EBSD data indicates that even up to 8 passes LAGBs still constitute a significant area fraction (Figure 6(a)). Therefore Eq. (4) merely fits mechanical data by increasing the H-P slope during the initial deformation stages when substructures enclose low misorientation angles [6]. Correspondingly the $k^{\prime}$-value is only an approximation as boundary character and its co-related size effects are not considered over all passes [65]. From the above it is understood that microstructure - mechanical property correlations estimated from the composite H-P equation (Eq. (3)) account for both, LAGB and HAGB deformation substructures.

\section{Conclusions}

The deformation microstructure and corresponding mechanical property relationships were determined for IF-steel samples after 1 pass, 4 passes and/or up to 8 passes via routes $A, B_{A}, B_{C}$ and $\mathrm{C}$ at $\Phi=90^{\circ} \mathrm{ECAE}$ and are summarised as follows:

1. Although the rates of $H A G B$ formation vary with processing route $\left(B_{C} \geq B_{A}>A>C\right.$ at $\left.N=4\right)$, the overall trends suggest a marked increase in HAGB area fraction with greater pass number.

2. During multi-pass ECAE, significant microstructural refinement continues to occur until a convergence in effective subgrain and grain diameters. Following this phenomenon, the rate of HAGB formation was also found to reduce slightly. 
3. Assessment of the grain boundary character distribution suggests that the appearance of $\Sigma 3$ boundaries should be correlated with recovery during ECAE.

4. The H-P analyses underline the importance of the misorientation angle as the delineating parameter with which to correlate microstructural refinement and mechanical property information. Both, the composite (Eq. (3)) and scaling factor (Eq. (4)) equations are reasonable for up to 3 passes; when the deformation substructure comprises predominantly LAGBs and its mechanical properties correspond to the subgrain size. However only the H-P relationship estimated by the composite equation accounts for a 'mixed' LAGB+HAGB deformation substructure. Beyond $\mathrm{N} \geq 4$ the increases in strength can be attributed to subgrain and grain diameters.

\section{Acknowledgments}

The authors are very grateful to Dr. Andrew Sullivan (Deakin University, Australia) for conducting the EBSD scans, Dr. Mark Nave for his helpful discussion on the EBSD software and Prof. F.J. Humphreys (University of Manchester, United Kingdom) for the VMAP software package. This work was partially funded by the Victorian Centre for Advanced Materials and Manufacturing (VCAMM) and the ARC Discovery Project 0557255.

\section{References}

[1] N. Hansen, Mat. Sci. Tech. 6 (1990) 1039-1040.

[2] F. J. Humphreys, Scr. Mater. 51 (2004) 771-776.

[3] W. Q. Cao, A. Godfrey, Q. Liu, Mater. Sci. Eng. A 361 (2003) 9-14.

[4] G. Wang, S. D. Wu, L. Zuo, C. Esling, Z. G. Wang, G. Y. Li, Mat. Sci. Eng. A 346 (2003) 83-90.

[5] A. L. Etter, T. Baudin, C. Rey, R. Penelle, Mat. Char. 56 (2006) 19-25.

[6] N. Hansen, Scr. Mater. 51 (2004) 801-806.

[7] B. L. Li, W. Q. Cao, Q. Liu, W. Liu, Mat. Sci. Eng. A 356 (2003) 37-42. 
[8] S. Li, A. A. Gazder, I. J. Beyerlein, C. H. J. Davies, E. V. Pereloma, Acta Mater. 54 (2006) 1087-1100.

[9] S. Li, A. A. Gazder, I. J. Beyerlein, C. H. J. Davies, E. V. Pereloma, Acta Mater. 55 (2007) 1017-1032.

[10] F. J. Humphreys, VMAP Handbook, University of Manchester, 2002.

[11] F. J. Humphreys, J. Mat. Sci. 36 (2001) 3833-3854.

[12] J. R. Bowen, The Formation of Ultra-fine Grained Model Aluminium and Steel Alloys, PhD. Thesis, University of Manchester Institute of Science and Technology, 2000.

[13] F. B. Pickering, The Basis of Quantitative Metallography, Institute of Metallurgical Technicians, London, 1976.

[14] D. G. Brandon, Acta Metall. 14 (1966) 1479-1966.

[15] G. E. Deiter, Mechanical Metallurgy, McGraw-Hill Book Company, Singapore, 1988.

[16] R. Z. Valiev, A. V. Korznikov, R. R. Mulyukov, Mater. Sci. Eng. A 168 (1993) 141-148.

[17] N. A. Akhmadeev, N. P. Kobelev, R. R. Mulyukov, Y. M. Soifer, R. Z. Valiev, Acta Metall. et Mater. 41 (1993) 1041-1046.

[18] R. Z. Valiev, Nano. Mat. 6 (1995) 73-82.

[19] A. B. Lebedev, Y. A. Burenkov, A. E. Romanov, V. I. Kopylov, V. P. Filonenko, V. G. Gryaznov, Mat. Sci. Eng. A 203 (1995) 165-170.

[20] A. A. Gazder, The Mechanical, Microstructure and Texture Properties of Interstitial-Free Steel subjected to Equal Channel Angular Extrusion, PhD. Thesis, Monash University, Melbourne, 2007.

[21] S. Li, B. R. Donohue, S. R. Kalidindi, Mat. Sci. Eng. A 480 (2008) 17-23.

[22] S. Li, I. J. Beyerlein, C. T. Necker, Acta Mater. 54 (2006) 1397-1408.

[23] M. Nave, Personal Communication, Melbourne, 2007.

[24] J.-Y. Chang, J.-S. Yoon, G.-H. Kim, Scr. Mater. 45 (2001) 347-354. 
[25] S. D. Terhune, D. L. Swisher, K. Oh-Ishi, Z. Horita, T. G. Langdon, T. R. McNelley, Metall. Mat. Trans. A 33 (2002) 2173-2184.

[26] A. Gholina, P. B. Prangnell, M. V. Markushev, Acta Mater. 48 (2000) 1115-1130.

[27] J. C. Huang, I. C. Hsiao, T. D. Wang, B. Y. Lou, Scr. Mater. 43 (2000) 213-220.

[28] A. P. Zhilyaev, B.-K. Kim, G. V. Nurislamova, M. D. Baró, J. A. Szpunar, T. G. Langdon, Scr. Mater. 46 (2002) 575-580.

[29] Y. V. Ivanisenko, R. Z. Valiev, H.-J. Fecht, Mat. Sci. Eng. A 390 (2005) 159-165.

[30] Y. T. Zhu, T. C. Lowe, Mat. Sci. Eng. A 291 (2000) 46-53.

[31] S. Ferrasse, V. M. Segal, K. T. Hartwig, R. E. Goforth, Metall. Mat. Trans. A 28 (1997) 1047-1057.

[32] Y. Iwahashi, M. Furukawa, Z. Horita, M. Nemoto, T. G. Langdon, Metall. Mat. Trans. A 29 (1998) 22452252.

[33] Y. Iwahashi, Z. Horita, M. Nemoto, T. G. Langdon, Acta Mater. 45 (1997) 4733-4741.

[34] P. B. Prangnell, J. R. Bowen, P. J. Apps, Mat. Sci. Eng. A 375-377 (2004) 178-185.

[35] D. A. Hughes, N. Hansen, Acta Mater. 45 (1997) 3871-3886.

[36] D. A. Hughes, N. Hansen, Acta Mater. 48 (2000) 2985-3004

[37] M. A. Meyers, V. F. Nesterenko, J. C. LaSalvia, Q. Xue, Mat. Sci. Eng. A 317 (2001) 204-225.

[38] A. Mishra, V. Richard, F. Grégori, R. J. Asaro, M. A. Meyers, Mat. Sci. Eng. A 410-411 (2005) 290-298.

[39] P. B. Prangnell, J. R. Bowen, A. Gholinia, in: A. R. Dinesen, et al. (Eds.), Proceedings of the 22nd Risø International Symposium on Materials Science: Science of Metastable and Nanocrystalline Alloys Structure, Properties and Modelling, Denmark, 2001, pp. 105-126.

[40] P. L. Sun, P. W. Kao, C. P. Chang, Scr. Mater. 51 (2004) 565-570.

[41] A. P. Zhilyaev, D. L. Swisher, K. Oh-ishi, T. G. Langdon, T. R. McNelley, Mat. Sci. Eng. A 429 (2006) 137148. 
[42] J. D. Embury, Mat. Sci. Eng. A 175 (1994) 105-111.

[43] R. Z. Valiev, Y. V. Ivanisenko, E. F. Rauch, B. Baudelet, Acta Mater. 44 (1996) 4705-4712.

[44] P. B. Prangnell, J. S. Hayes, J. R. Bowen, P. J. Apps, P. S. Bate, Acta Mater. 52 (2004) 3193-3206.

[45] R. A. Mulford, U. F. Kocks, Acta Metall. 27 (1979) 1125-1134.

[46] F. H. DallaTorre, R. Lapovok, J. Sandlin, P. F. Thomson, C. H. J. Davies, E. V. Pereloma, Acta Mater. 52 (2004) 4819-4832.

[47] C. X. Huang, K. Wang, S. D. Wu, Z. F. Zhang, G. Y. Li, S. X. Li, Acta Mater. 54 (2006) 655-665.

[48] X. Z. Liao, Y. H. Zhao, S. G. Srinivasan, Y. T. Zhu, R. Z. Valiev, D. V. Gunderov, App. Phys. Let. 84 (2004) 592-594.

[49] X. Z. Liao, Y. H. Zhao, Y. T. Zhu, R. Z. Valiev, D. V. Gunderov, J. App. Phys. 96 (2004) 636-640.

[50] M. A. Meyers, L. E. Murr, Acta Metall. 26 (1978) 951-962.

[51] M. A. Meyers, O. Vöhringer, V. A. Lubarda, Acta Mater. 49 (2001) 4025-4039.

[52] F. H. DallaTorre, R. Lapovok, P. F. Thomson, J. Sandlin, C. H. J. Davies, E. V. Pereloma, in: P. M. Anderson, et al. (Eds.), Materials Research Society Symposium, USA, 2004, p. 9.10.

[53] F. H. DallaTorre, E. V. Pereloma, C. H. J. Davies, Acta Mater. 54 (2006) 1135-1146.

[54] E.O.Hall, Proc. Phy. Soc., Ser. B 64 (1951) 747-753.

[55] N. J. Petch, J. Iron Steel Inst. 174 (1953) 25-28.

[56] S. G. Tresvyatskii, Prob. Proch. 11 (1971) 60-63.

[57] W. F. Hosford, The Mechanics of Crystals and Textured Polycrystals, Oxford University Press, New York, 1993.

[58] J.-P. Baïlon, A. Loyer, J.-M. Dorlot, Mat. Sci. Eng. 8 (1971) 288-298.

[59] N. Hansen, Mat. Sci. Eng. A 409 (2005) 39-45. 
[60] J. D. Messemaeker, B. Verlinden, J. V. Humbeeck, Mat. Let. 58 (2004) 3782-3786.

[61] J. C. M. Li, Trans. Metall. Soc. AIME 227 (1963) 239-247.

[62] S. Takaki, K. Kawasaki, Y. Kimura, J. Mat. Pro. Tech. 117 (2001) 359-363.

[63] B. Q. Han, S. Yue, J. Mat. Pro. Tech. 136 (2003) 100-104.

[64] Y. J. Li, X. H. Zeng, W. Blum, Acta Mater. 52 (2004) 5009-5018.

[65] D. J. Abson, J. J. Jonas, Met. Sci. 4 (1970) 24-28. 


\section{Figures List}

Figure 1: Schematic of ECAE tooling with a half-way extruded billet indicating the adopted coordinate system for a $\Phi=90^{\circ}, \Psi=0^{\circ}$ die-set. (Not to scale)

Figure 2: EBSD map of IF-steel after $N=1$ at $\Phi=90^{\circ}$ ECAE. The strengths of the primary colours are proportional to the three Euler angles. The thin black lines are LAGBs while the thick black lines denote HAGBs.

Figure 3: EBSD maps of IF-steel after (a) $N=2$, (b) $N=3$, (c) $N=4$, (d) $N=5$, (e) $N=6$, (f) $N=7$ and, (g) $\mathrm{N}=8$ via route $\mathrm{B}_{\mathrm{C}}$ at $\Phi=90^{\circ}$ ECAE. The strengths of the primary colours are proportional to the three Euler angles. The thin black lines are LAGBs while the thick black lines denote HAGBs.

Figure 4: EBSD maps of IF-steel after $N=4$ via routes (a) $A$, (b) $B_{A}$ and, (c) $C$ at $\Phi=90^{\circ}$ ECAE. The strengths of the primary colours are proportional to the three Euler angles. The thin black lines are LAGBs while the thick black lines denote HAGBs.

Figure 5: Misorientation histograms after multiple passes via routes (a) $A$, (b) $B_{A},(c) B_{C}$ and, (d) $\mathrm{C}$ at $\Phi=90^{\circ} \mathrm{ECAE}$.

Figure 6: Change in the percentage area fraction $\left(A_{F} \%\right)$ of (a) $1^{\circ}-15^{\circ}$ (LAGBs) and, (b) $15^{\circ}-30^{\circ}$ (MAGBs), (c) $30^{\circ}-45^{\circ}$ (MHAGBs), (d) $45^{\circ}-62.8^{\circ}$ (VHAGBs) misorientation bins after multiple passes via routes $A, B_{A}, B_{C}$ and $C$ at $\Phi=90^{\circ} \mathrm{ECAE}$.

Figure 7: Change in average misorientation $(\theta)$ of (a) $1^{\circ}-62.8^{\circ}$ (or $\theta_{A V G}$ ), (b) $1^{\circ}-15^{\circ}$ (LAGBs) and, (c) $15^{\circ}-62.8^{\circ}$ (HAGBs) misorientation bins after multiple passes via routes $\mathrm{A}, \mathrm{B}_{\mathrm{A}}, \mathrm{B}_{\mathrm{C}}$ and $\mathrm{C}$ at $\Phi=$ $90^{\circ}$ ECAE. 
Figure 8: Change in the average effective diameter $(d)$ of (a) $1^{\circ}-62.8^{\circ}$ (or $d_{A V G}$ ), (b) $1^{\circ}-15^{\circ}$ (LAGBs) and, (c) $15^{\circ}-62.8^{\circ}$ (HAGBs) after multiple passes via routes $\mathrm{A}, \mathrm{B}_{\mathrm{A}}, \mathrm{B}_{\mathrm{C}}$ and $\mathrm{C}$ at $\Phi=90^{\circ}$ ECAE. (d) A magnified view of the close correlation between the EBSD-returned effective diameters $d_{1^{\circ}-15^{\circ}}$ and $d_{15^{\circ}-62.8^{\circ}}$ for up to $\mathrm{N}=8$ via route $\mathrm{B}_{\mathrm{C}}$ at $\Phi=90^{\circ} \mathrm{ECAE}$.

Figure 9: Change in the average aspect ratios $(\lambda)$ after multiple passes via routes $A, B_{A}, B_{C}$ and, $C$ at $\Phi=90^{\circ} \mathrm{ECAE}$.

Figure 10: (a) Experimental and predicted 0.1\% proof $\left(\sigma_{0.1}\right), 0.2 \%$ proof $\left(\sigma_{0.2}\right)$ and ultimate tensile $\left(\sigma_{U T S}\right)$ stresses using the composite Hall-Petch equation (Eq. (3)) and, (b) the additive linear strengthening contributions from $\sigma_{0}$, LAGBs and HAGBs after multiple passes via route $\mathrm{B}_{\mathrm{C}}$ at $\Phi=90^{\circ} \mathrm{ECAE}$.

Figure 11: The relationship between the experimental $0.2 \%$ proof stress $\left(\sigma_{0.2}\right)$ and the EBSDreturned average subgrain diameter $\left(d_{1^{\circ}-15^{\circ}}\right)$ according to the scaling factor Hall-Petch equation (Eq. (4)). 


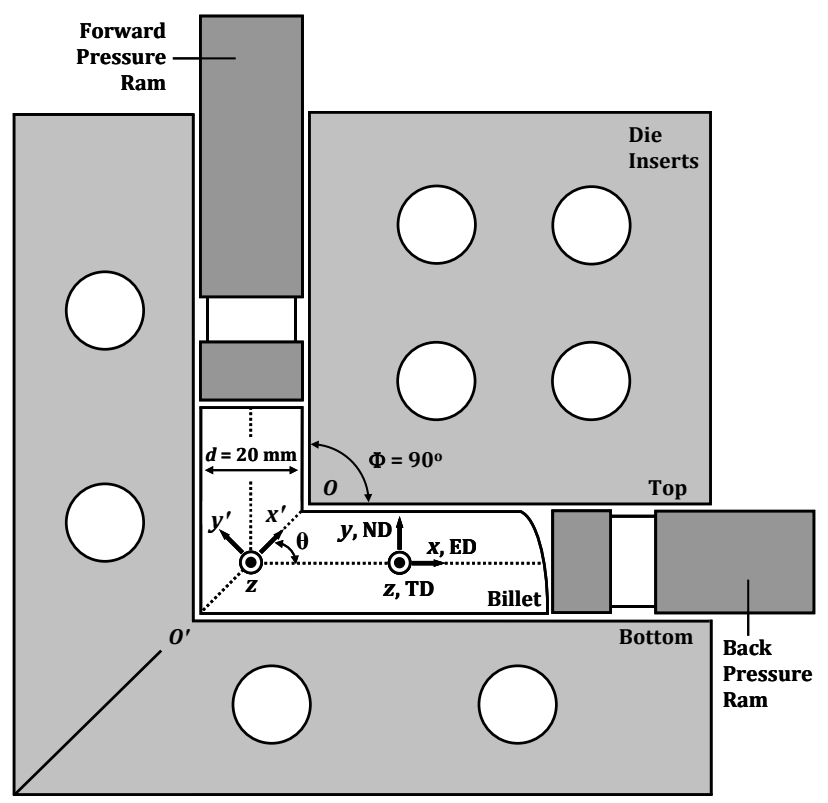

Figure 1: Schematic of ECAE tooling with a half-way extruded billet indicating the adopted coordinate system for a $\Phi=90^{\circ}, \Psi=0^{\circ}$ die-set. (Not to scale) 


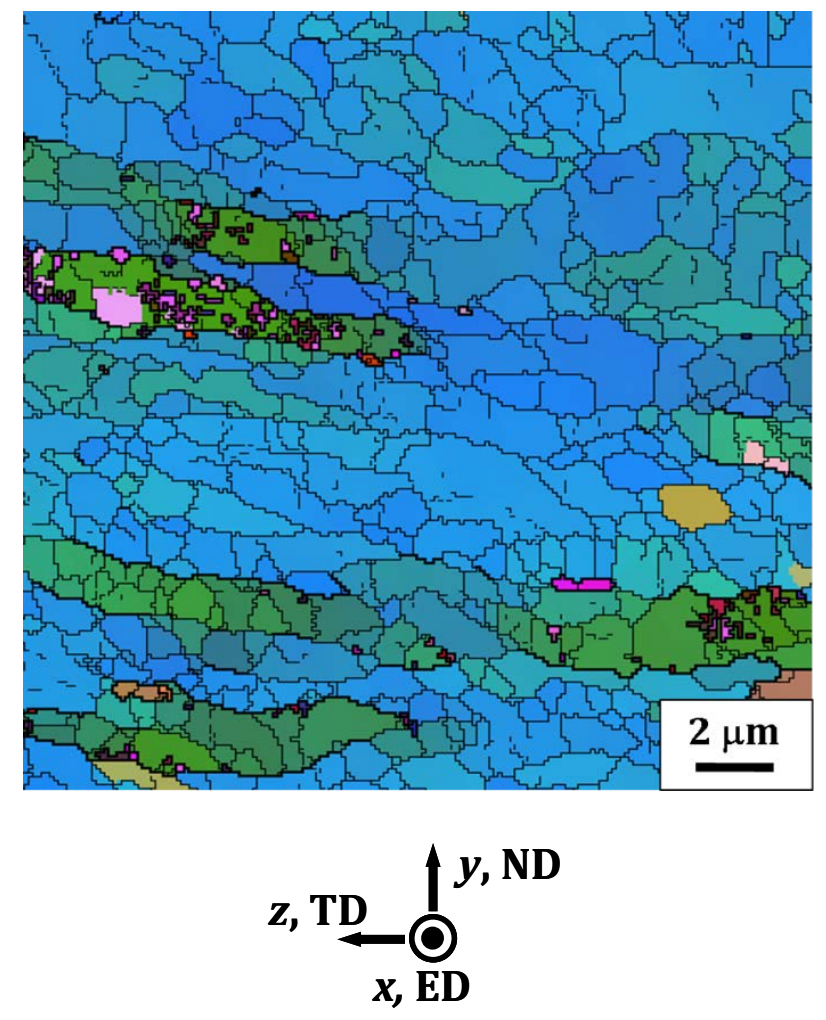

Figure 2: EBSD map of IF-steel after $\mathrm{N}=1$ at $\Phi=90^{\circ}$ ECAE. The strengths of the primary colours are proportional to the three Euler angles. The thin black lines are LAGBs while the thick black lines denote HAGBs. 


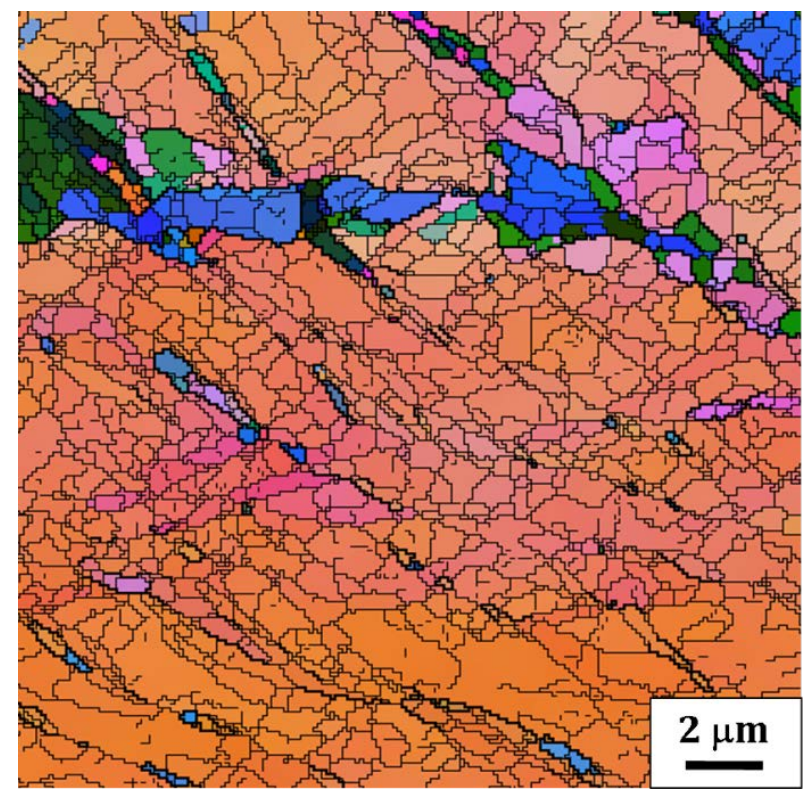

(a)

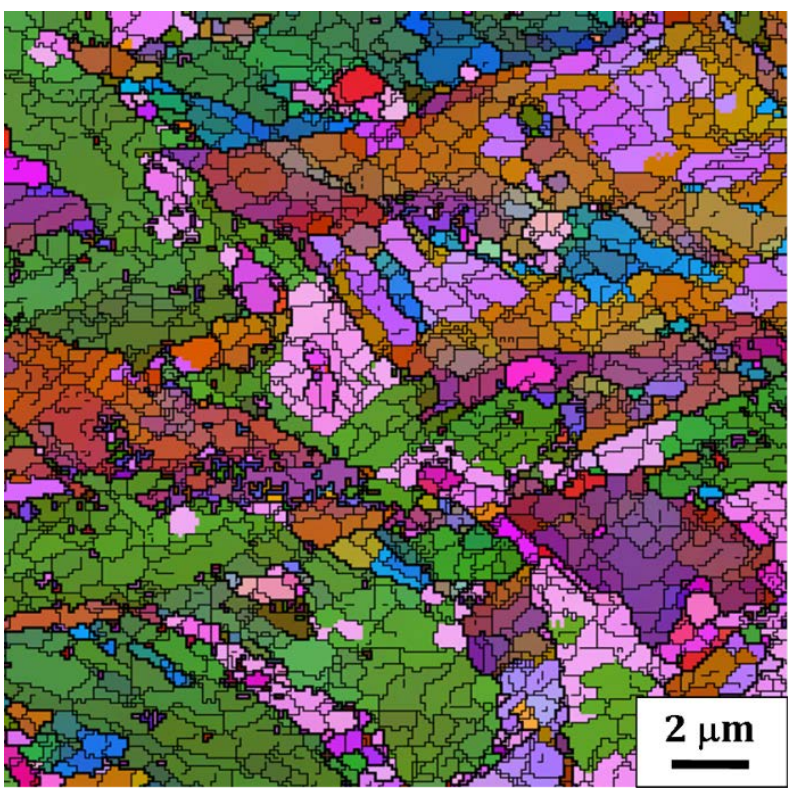

(b)

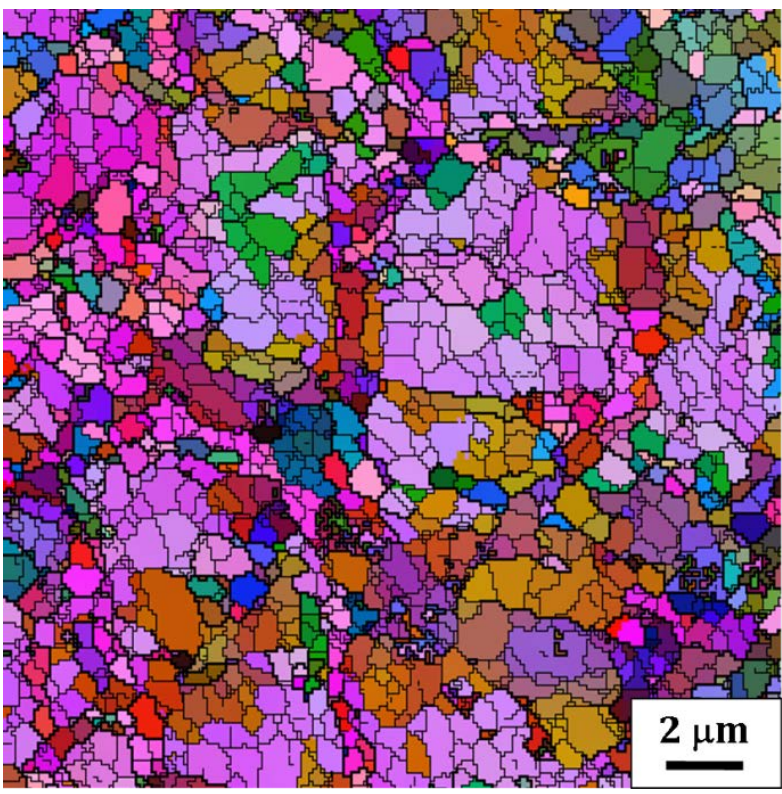

(c)

Figure 3 contd. 


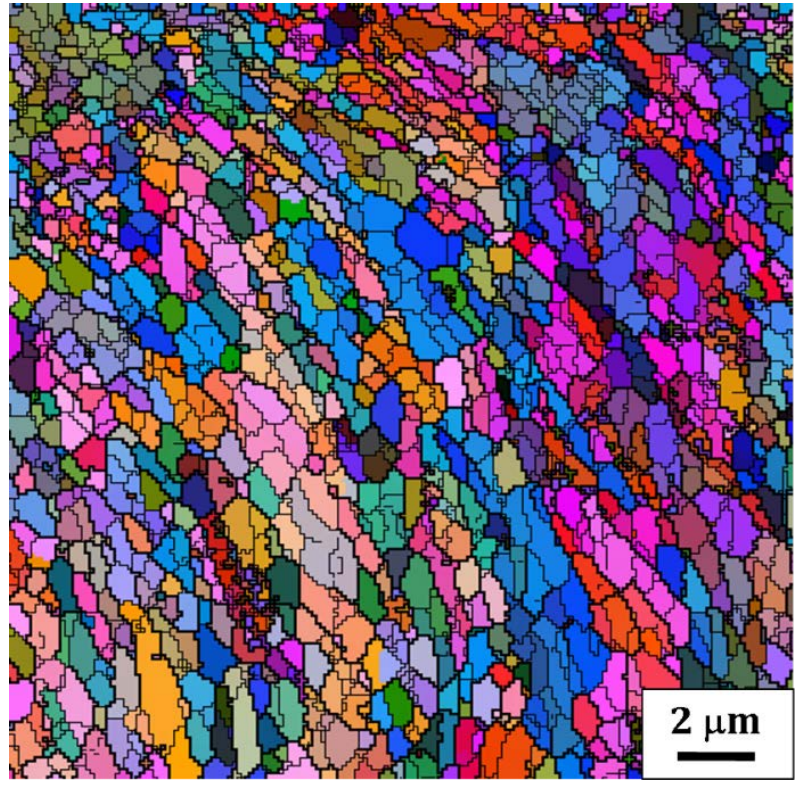

(d)

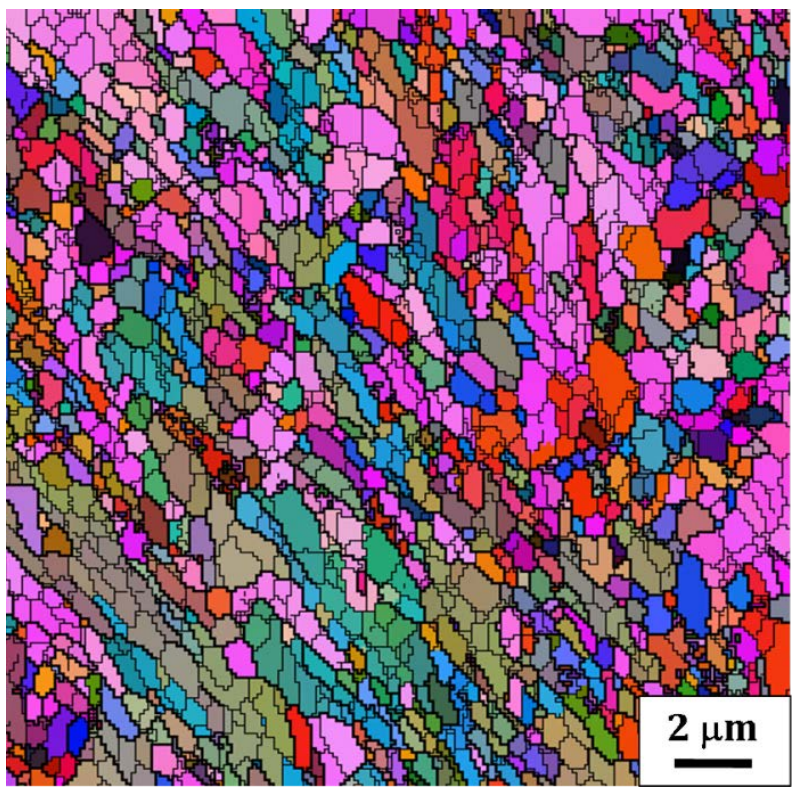

(f)

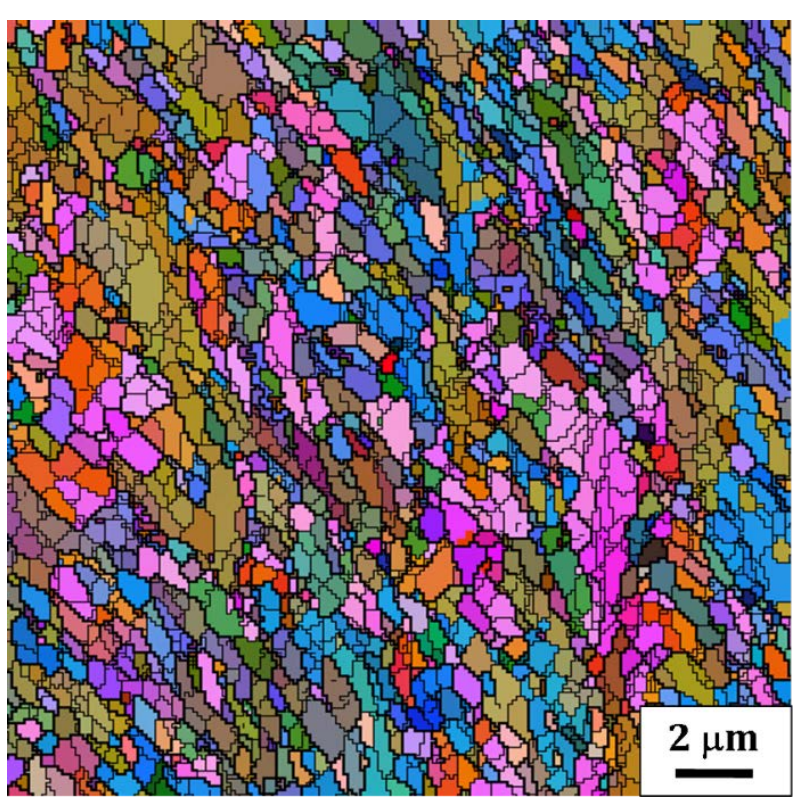

(e)

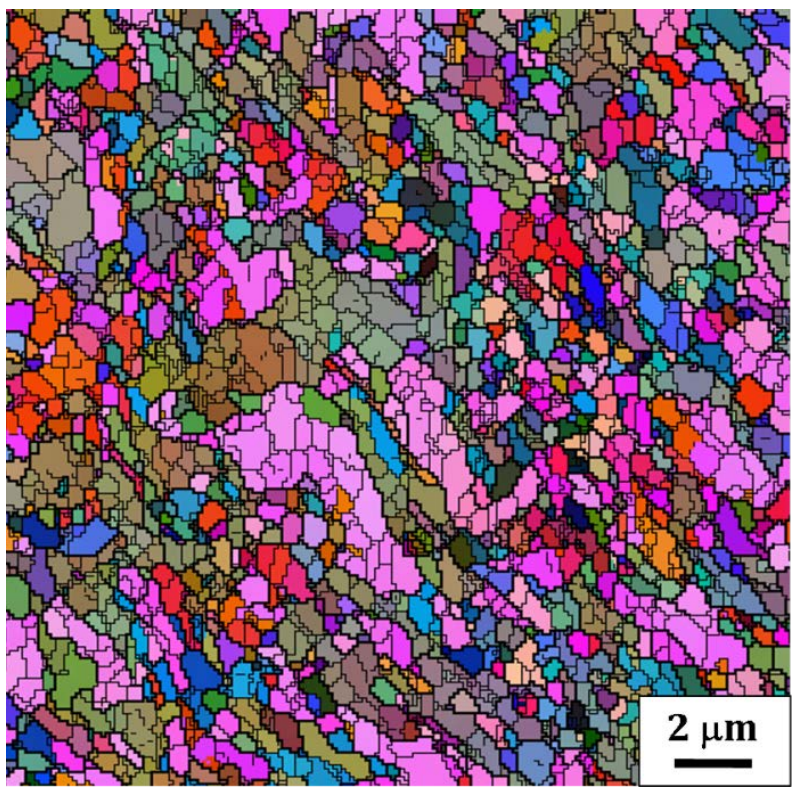

(g)

\section{$z, \underbrace{\bigoplus_{(}^{y, N D}}_{x, \mathrm{ED}}$}

Figure 3: EBSD maps of IF-steel after (a) $N=2$, (b) $N=3$, (c) $N=4$, (d) $N=5$, (e) $N=6$, (f) $N=7$ and, $(\mathrm{g}) \mathrm{N}=8$ via route $\mathrm{B}_{\mathrm{C}}$ at $\Phi=90^{\circ}$ ECAE. The strengths of the primary colours are proportional to the three Euler angles. The thin black lines are LAGBs while the thick black lines denote HAGBs. 
(a)
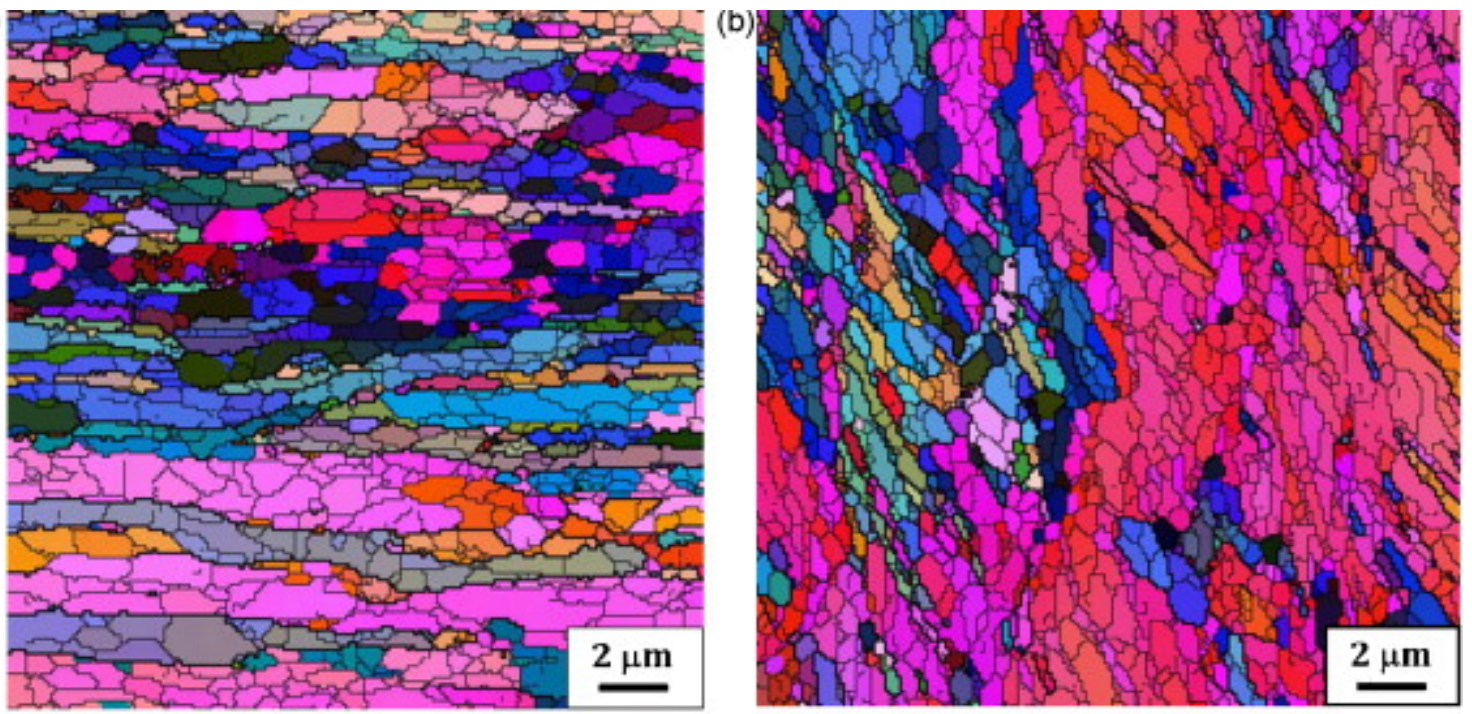

(c)
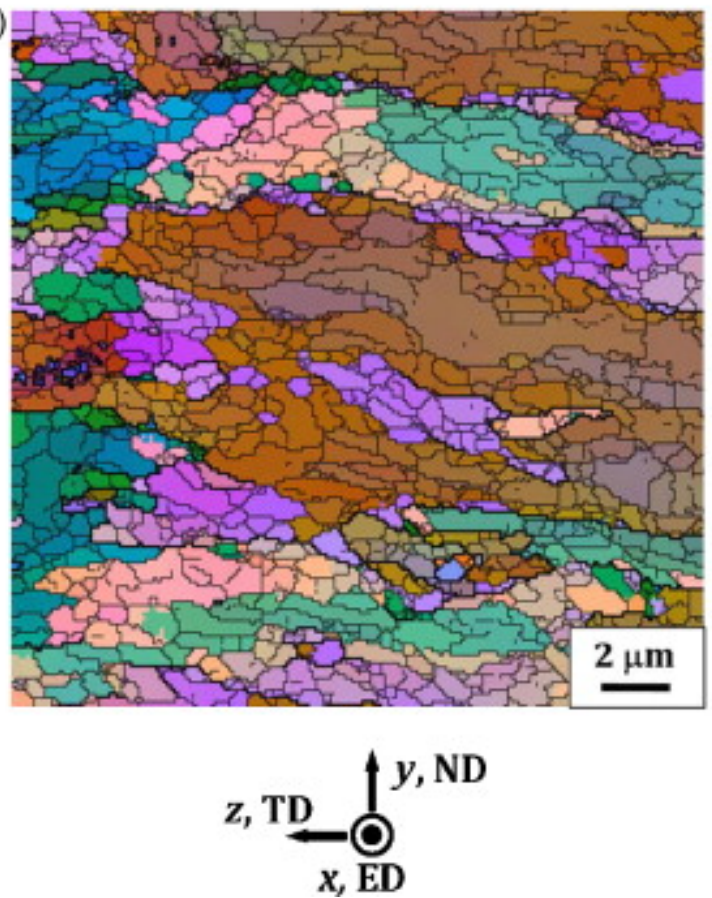

Figure 4: EBSD maps of IF-steel after $N=4$ via routes (a) $A$, (b) $B_{A}$ and, (c) $C$ at $\Phi=90^{\circ}$ ECAE. The strengths of the primary colours are proportional to the three Euler angles. The thin black lines are LAGBs while the thick black lines denote HAGBs. 

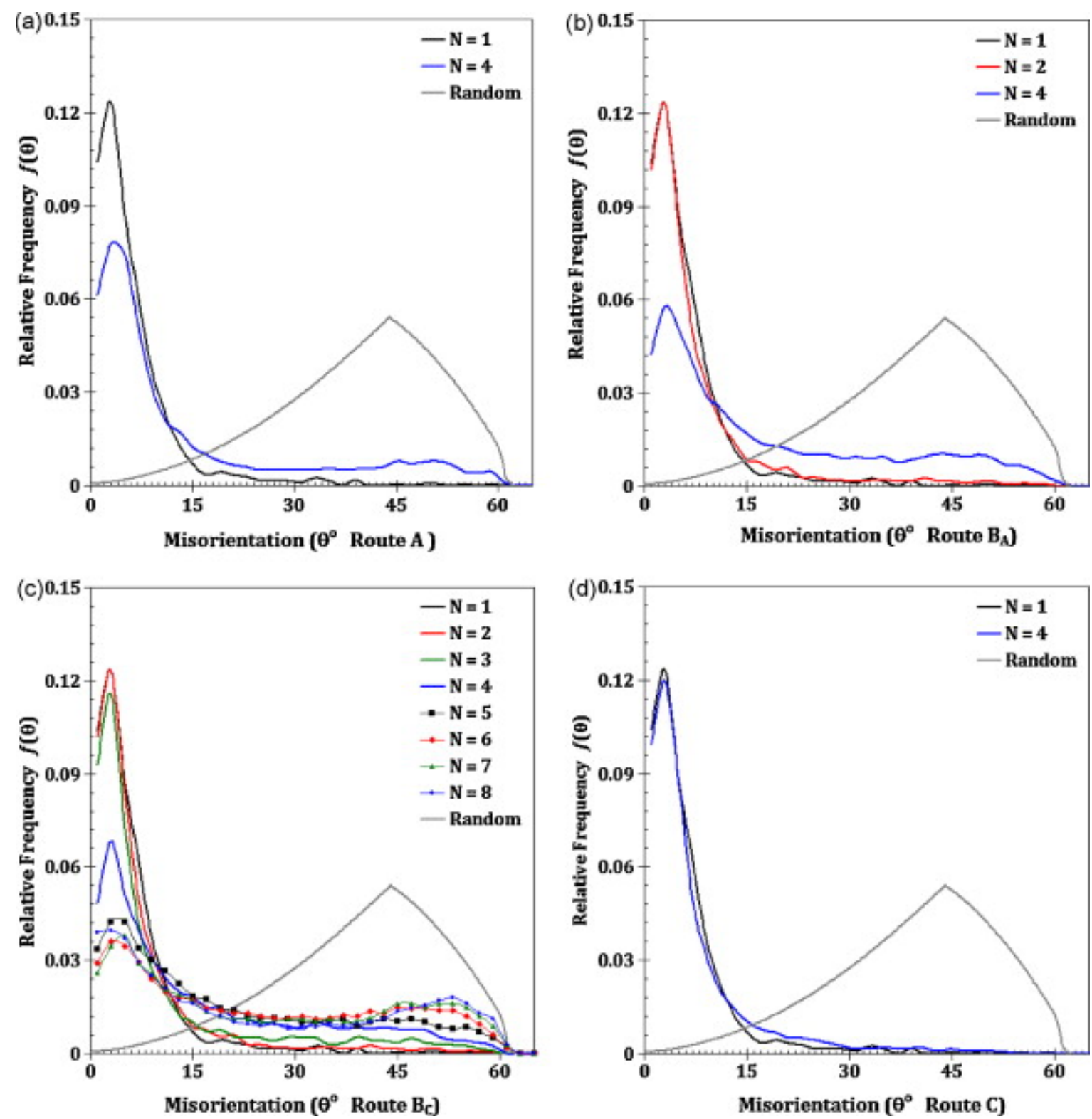

Figure 5: Change in the misorientation distribution after multiple passes via routes (a) $A,(b) B_{A}$, (c) $\mathrm{B}_{\mathrm{C}}$ and, (d) C at $\Phi=90^{\circ} \mathrm{ECAE}$. 

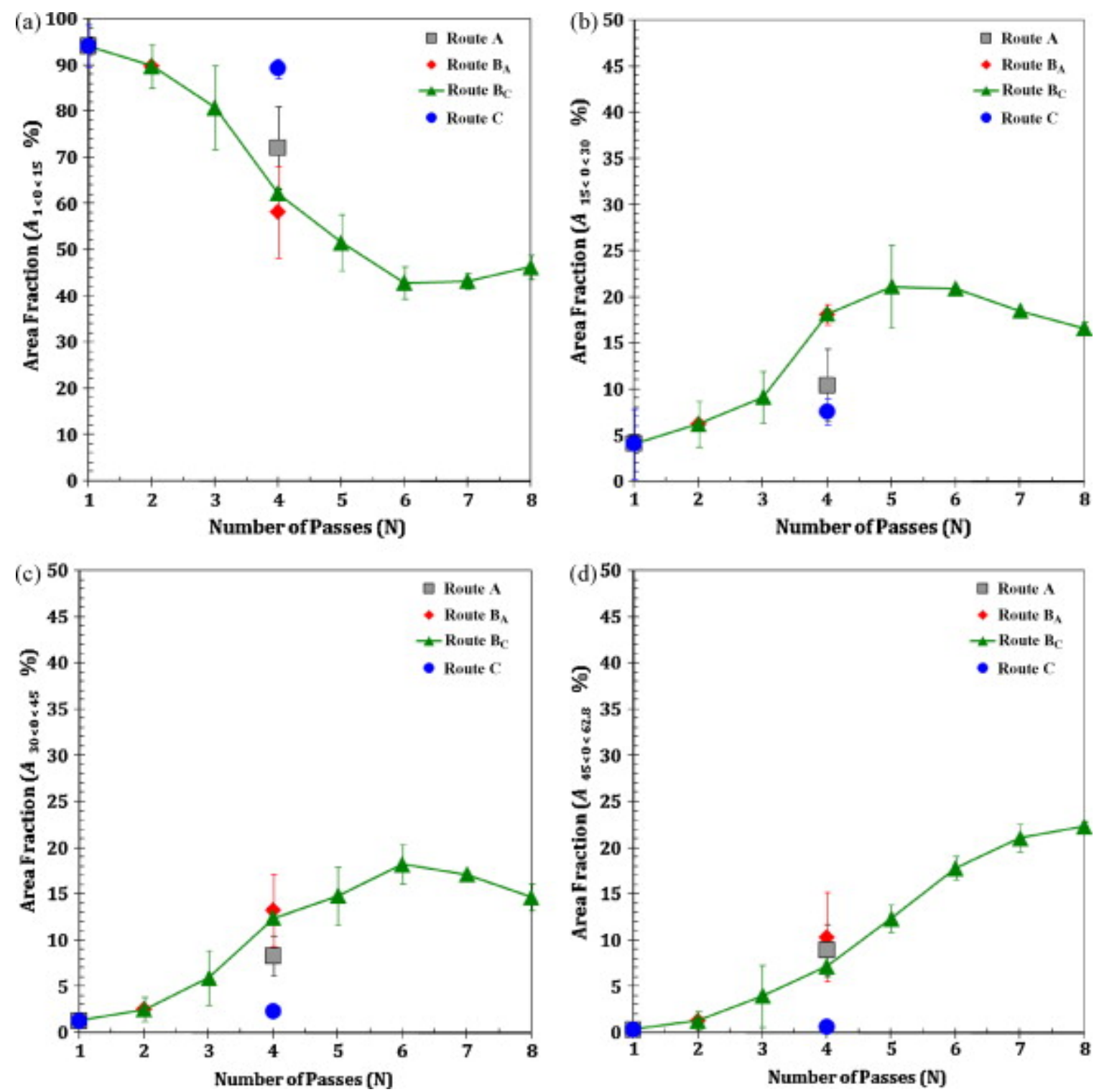

Figure 6: Change in the percentage area fraction $\left(\mathrm{A}_{\mathrm{F}} \%\right.$ ) of (a) $1^{\circ}-15^{\circ}$ (LAGBs) and, (b) $15^{\circ}-30^{\circ}$ (MAGBs), (c) $30^{\circ}-45^{\circ}$ (MHAGBs), (d) $45^{\circ}-62.8^{\circ}$ (VHAGBs) misorientation bins after multiple passes via routes $A, B_{A}, B_{C}$ and $C$ at $\Phi=90^{\circ}$ ECAE. 

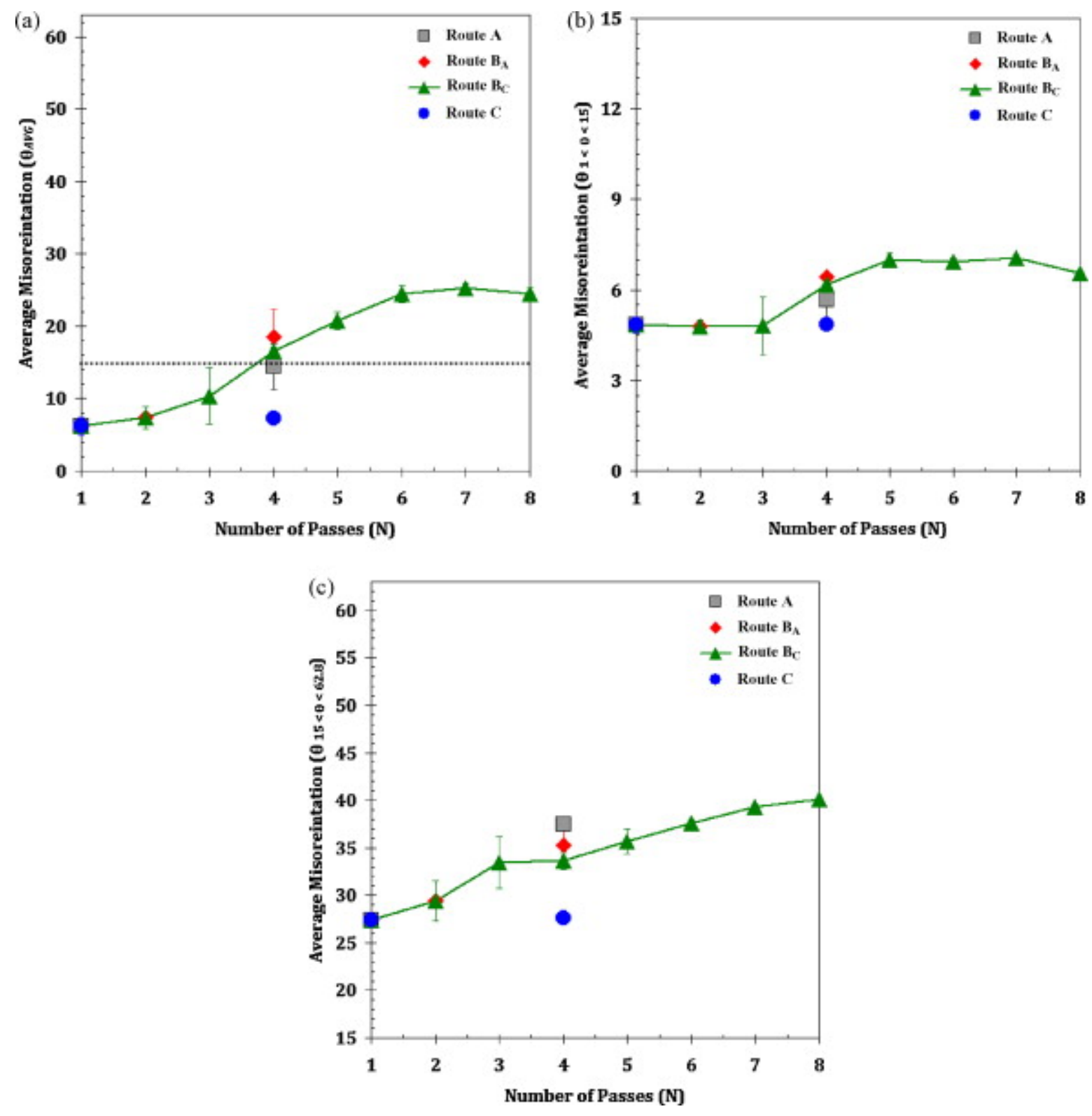

Figure 7: Change in the average misorientation $(\theta)$ of (a) $1^{\circ}-62.8^{\circ}$ (or $\theta_{\mathrm{AVG}}$ ), (b) $1^{\circ}-15^{\circ}$ (LAGBs) and, (c) $15^{\circ}-62.8^{\circ}$ (HAGBs) misorientation bins after multiple passes via routes $A, B_{A}, B_{C}$ and $C$ at $\Phi=90^{\circ} \mathrm{ECAE}$. 

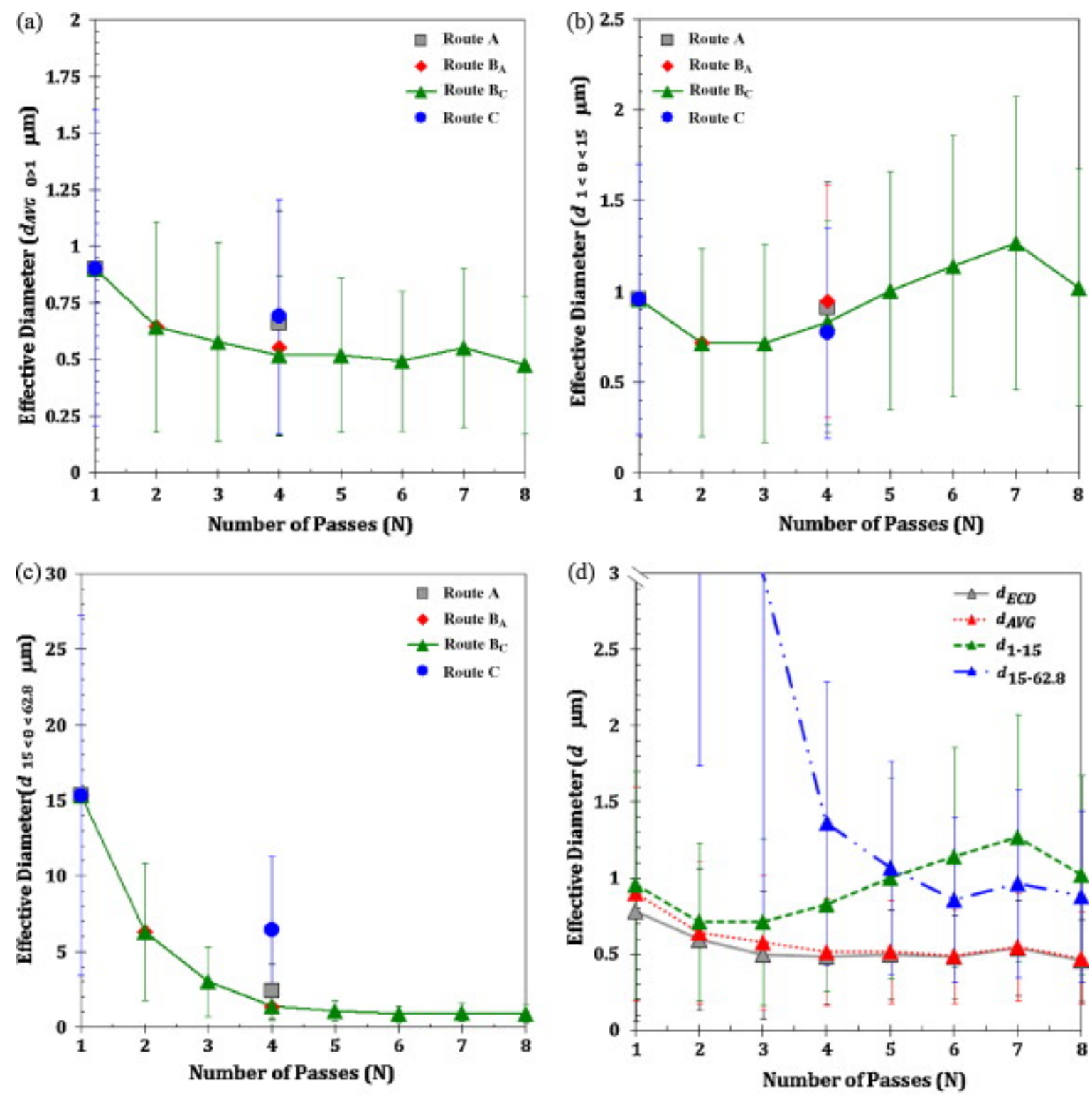

Figure 8: Change in the average effective diameter (d) of (a) $1^{\circ}-62.8^{\circ}\left(\right.$ or $\mathrm{d}_{\mathrm{AVG}}$ ), (b) $1^{\circ}-15^{\circ}$ (LAGBs) and, (c) $15^{\circ}-62.8^{\circ}$ (HAGBs) after multiple passes via routes $\mathrm{A}, \mathrm{B}_{\mathrm{A}}, \mathrm{B}_{\mathrm{C}}$ and $\mathrm{C}$ at $\Phi=90^{\circ}$ ECAE. (d) A magnified view of the close correlation between the EBSD-returned effective diameters $\mathrm{d}_{1^{\circ}-15^{\circ}}$ and $\mathrm{d}_{15^{\circ}-62.8^{\circ}}$ for up to $\mathrm{N}=8$ via route $\mathrm{B}_{\mathrm{C}}$ at $\Phi=90^{\circ} \mathrm{ECAE}$. 


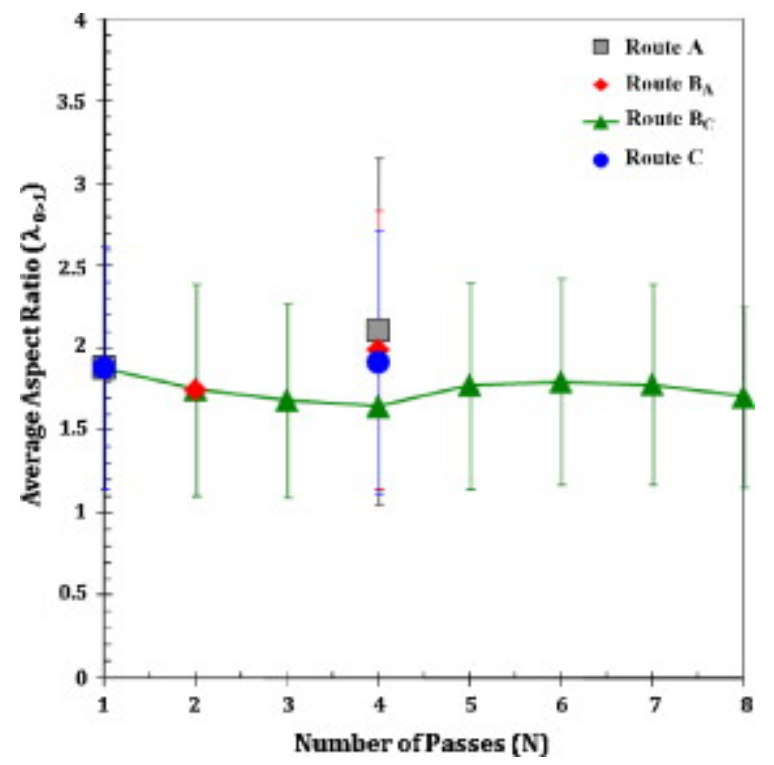

Figure 9: Change in the average aspect ratios $(\lambda)$ after multiple passes via routes $A, B_{A}, B_{C}$ and, $C$ at $\Phi=90^{\circ} \mathrm{ECAE}$.
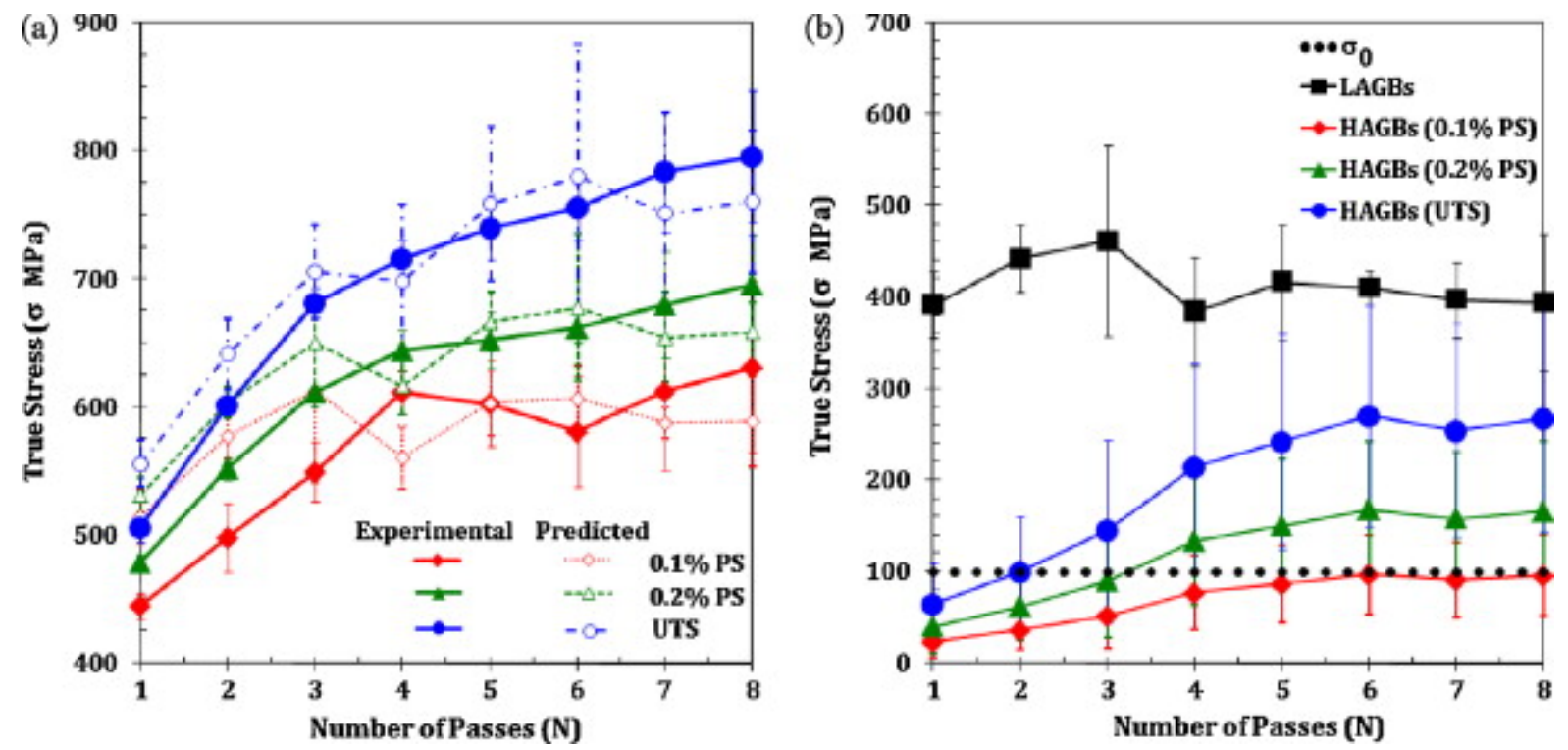

Figure 10: (a) Experimental and predicted $0.1 \%$ proof $\left(\sigma_{0.1}\right), 0.2 \%$ proof $\left(\sigma_{0.2}\right)$ and ultimate tensile ( $\sigma_{\mathrm{UTS}}$ ) stresses using the composite Hall-Petch equation (Eq. (3)) and, (b) the additive linear strengthening contributions from $\sigma_{0}$, LAGBs and HAGBs after multiple passes via route $\mathrm{B}_{\mathrm{C}}$ at $\Phi=90^{\circ} \mathrm{ECAE}$. 


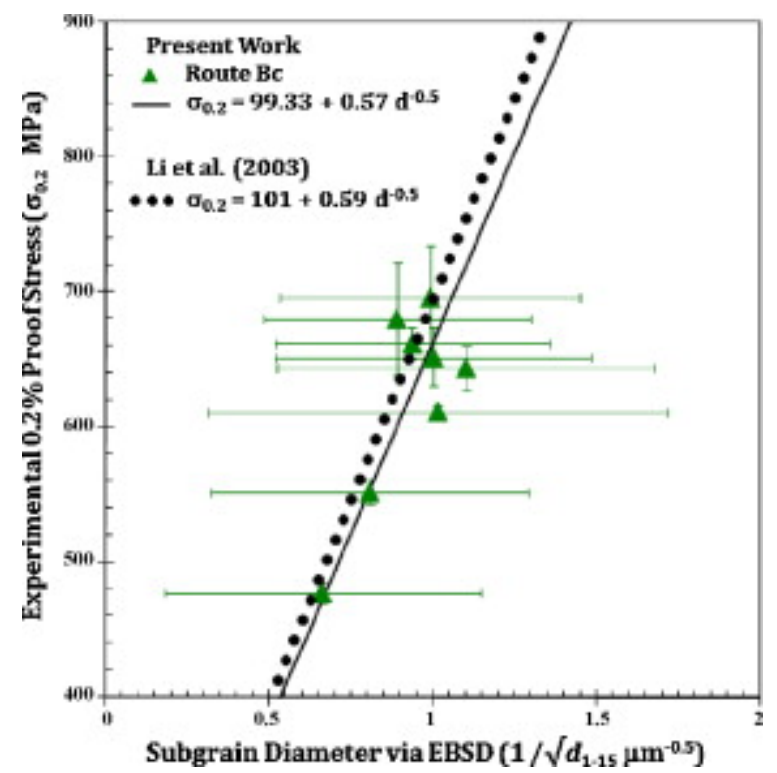

Figure 11: The relationship between the experimental $0.2 \%$ proof stress $\left(\sigma_{0.2}\right)$ and the EBSDreturned average subgrain diameter $\left(\mathrm{d}_{1^{\circ}-15^{\circ}}\right)$ according to the scaling factor Hall-Petch equation (Eq. (4)).

\section{Tables List}

Table 1: Grain boundary character distribution $(\Sigma)$ using the Brandon criterion for up to $N=4$ and 8 via routes $\mathrm{A}, \mathrm{B}_{\mathrm{A}}, \mathrm{B}_{\mathrm{C}}$ and $\mathrm{C}$ at $\Phi=90^{\circ} \mathrm{ECAE}$. 


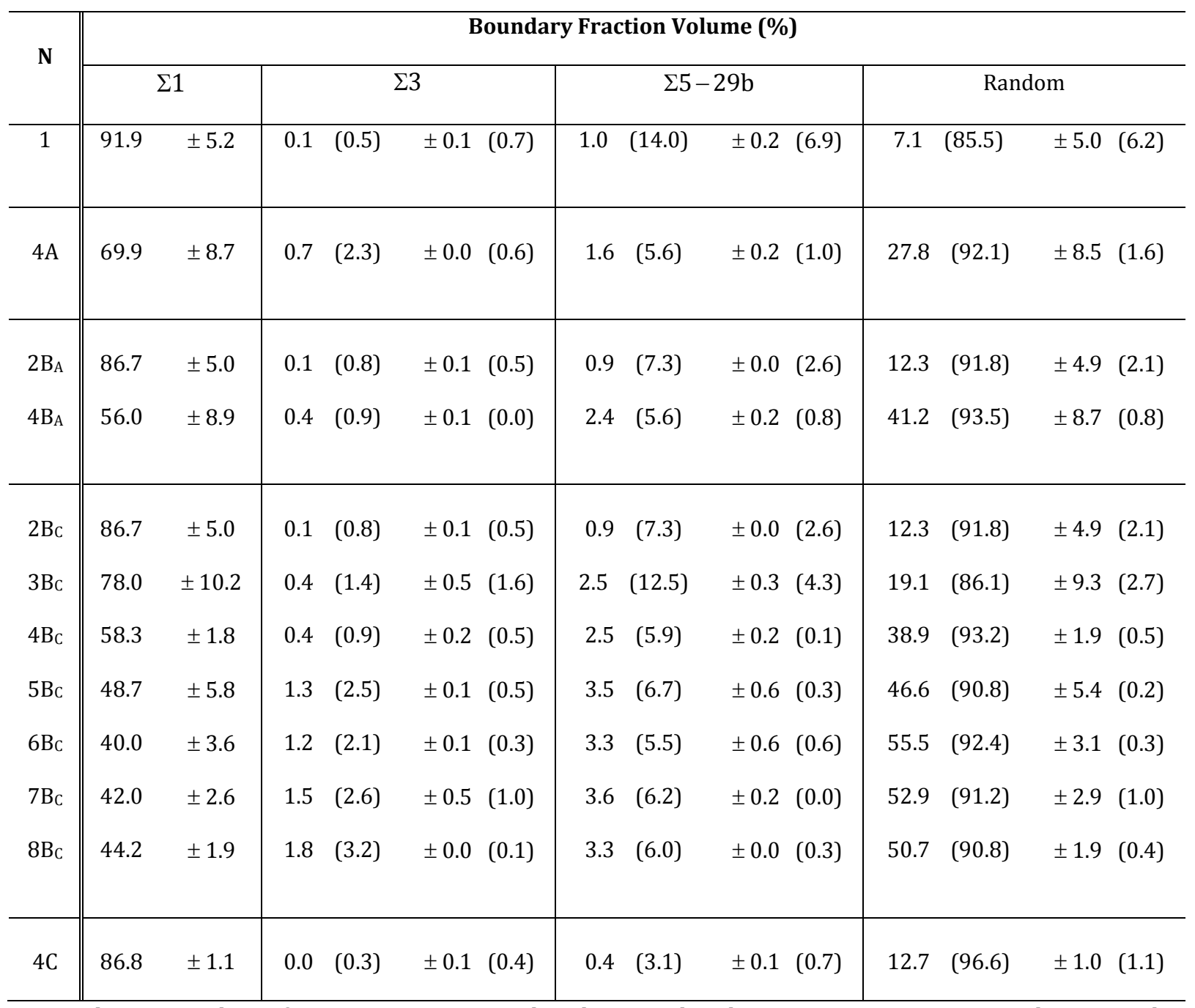

Legend: $\mathrm{N}=$ number of passes; $\mathrm{A}, \mathrm{B}_{\mathrm{A}}, \mathrm{B}_{\mathrm{C}}$ and $\mathrm{C}$ denotes the chosen processing route. Values outside parenthesis are estimates for all boundaries whereas values within them refer only to HAGBs. All values have been rounded-off to one significant digit. 